\title{
I. Kommunisten und Bauern in der sowjetischen Besatzungszone 1945 bis 1948
}

\section{Ausgangsbedingungen}

\section{Zur Situation der Landwirtschaft bei Kriegsende}

Das von den sowjetischen Truppen eingenommene Territorium der späteren SBZ genoß in den Überlegungen der sowjetischen Besatzungspolitik im Frühjahr 1945 eine hervorgehobene Rolle. Stalin betrachtete dieses Gebiet Deutschlands als solches, das im Unterschied zu den abgetrennten östlichen Reichsgebieten nicht dauerhaft mit rigiden sowjetischen Herrschaftsmethoden zu unterwerfen sein würde. $\mathrm{Zu}$ seiner Bevölkerung mußten die Besatzer daher ein auskömmliches Verhältnis finden ${ }^{1}$. Freilich lebte hier eine "Zusammenbruchgesellschaft" ${ }^{2}$, ein Begriff, der auch die Verhältnisse in der ländlichen Welt charakterisiert.

Aus dem Land transportierten sowjetische Soldaten ab, was beweglich war Nutz- und Zugtiere, Traktoren, Maschinen und andere Betriebsmittel, die wiederum für eine geregelte Ernte und die dringend nötige Ernährungssicherung fehlten. In Berlin sei im Juni offenbar halbwegs Ruhe eingekehrt, „auf dem flachen Lande allerdings scheinen sich die Verhältnisse noch keineswegs überall so günstig anzulassen“, hielt man im Umkreis des Berliner Haupternährungsamtes fest $^{3}$. Im Unterschied zu den westlichen Besatzungszonen waren Teile der späteren SBZ, vor allem im östlichen Mecklenburg und Brandenburg, unmittelbarer Schauplatz der verheerenden Kriegshandlungen gewesen. Dort stieß man häufig auf verminte oder von Geschützgräben durchzogene Ackerflächen ${ }^{4}$. Ausgezehrt von den Anforderungen der nationalsozialistischen „Erzeugungsschlachten“, war ein Großteil der landwirtschaftlichen Nutzfläche und der Betriebe schwer in Mitleidenschaft gezogen worden, aber in der betriebswirtschaftlichen Substanz noch intakt. Die Frühjahrsbestellungen 1945 konnten wegen der Kampfhandlungen nicht richtig durchgeführt werden, die Ernte fiel mager aus, und der Mangel an Dünger, Saatgut, schwerem Gerät und menschlicher Arbeitskraft, der die Herbstbestellung 1945 behinderte, kündigte für das folgende Jahr eine noch schlechtere Ernährungslage $a^{5}$. Willkürliche Plünderungen und Brandstiftungen sowjeti-

1 Vgl. sssR i germanski vopros, Bd. 1; Zeidler, Kriegsende, S. 155-167; Naimark, Russians, S. 76; diese Zäsur ist auch in der sowjetischen Internierungspolitik abzulesen, Sowjetische Speziallager, Bd. 2, Einleitung S. 15, Dok. 18 u. 19, S. $174 \mathrm{f}$.

2 Kleßmann, Staatsgründung, S. 37.

3 Keiderling (Hg.), „Gruppe Ulbricht“, Bericht zur „Lage im russischen Raum“, S. 601618, bes. S. 616, Zitat S. 601.

4 So für den Kreis Neubrandenburg, Woderich, Junkerdorf, S. $14 \mathrm{f}$.

5 Zur Situation 1945, für Brandenburg: Bauerkämper, Bodenreform in der Provinz Mark Brandenburg, S. 266; für Mecklenburg: ders., Antinomien, S. 367; für Sachsen: Kluge, 
scher Soldaten verschlimmerten die Kriegsschäden ${ }^{6}$; die anhaltenden gewalttätigen Übergriffe vor allem gegen Frauen, aber auch gegen Männer hinterließen tiefe Spuren ${ }^{7}$. Häufig stifteten diese Erlebnisse lebenslange Traumata und konterkarierten die von der Propaganda hochgehaltene deutsch-sowjetische Freundschaft ${ }^{8}$.

Bislang liegt keine umfassende Bestandsaufnahme der agrarökonomischen Lage 1945 vor, schon gar nicht auf neuer Aktenbasis. Einzeldaten gestatten daher nur einen begrenzten Einblick: Bezogen auf das Jahr 1943 meldete die erste Viehbestandserhebung 1946 für die Bestände an Pferden 91\%, Rindvieh 78\%, Kühen $70 \%$, Schweinen $49 \%$ und Schafen $41 \%$. Die Viehverluste lagen damit erheblich über denjenigen im westlichen Besatzungsgebiet ${ }^{9}$. Freilich gab es starke regionale Unterschiede. In den Kriegsgebieten war der Viehbestand häufig auf die Hälfte dezimiert, die wertvollen Herdbuchbestände großer ostelbischer Güter wurden zum Teil kurzsichtig weggetrieben und kamen um. Das Ackerland war schon von 1938 bis 1946 um rund $5 \%$ geschrumpft ${ }^{10}$. Dem schlechten Bodenzustand trug man in den folgenden Jahren insofern Rechnung, als der Anbau fruchtbarkeitsmehrender Pflanzen auf Kosten des Anbaus fruchtbarkeitszehrender relativ ausgedehnt wurde ${ }^{11}$. Das vormalige Reichsgebiet hatte auch zu Zeiten der Kriegswirtschaft dank eines rigiden aber systematischen Kontingentierungs- und Erfassungssystems und aufgrund der Ausbeutung ausländischer Zwangs- und Fremdarbeiter bis zuletzt landwirtschaftliche Überschüsse produziert, die in das Altreich flossen ${ }^{12}$. Unter den Bedingungen des Jahres 1945 war hingegen die Subsistenzwirtschaft auf dem Vormarsch.

Nach Kriegsende war die Landwirtschaft von einem Großteil ihrer bisherigen Arbeitskräfte entblößt. Viele Gutsbesitzerfamilien waren vor der heranrückenden Roten Armee geflohen, ausländische Arbeiter traten überwiegend den Nachhauseweg an. Wenngleich Flüchtlinge und Vertriebene in diese Lücken stießen, so entstanden neue Probleme. Die Flüchtlings- und Vertriebenenzüge strömten stärker in die dünn besiedelten agrarischen Gebiete von Mecklenburg-Vorpommern

„Die Bodenreform ist in erster Linie“, S. 104 f.; Barthel, Ausgangsbedingungen, S. 44-49; Wernet-Tietz, Bauernverband, S. 28.

${ }^{6}$ Kramer, Bolschewisierung, S. $86 \mathrm{f}$.

7 Zum Problem der Vergewaltigungen: Naimark, Russians, S. 69-140; siehe auch Foitzik, Struktur, S. 67-75.

${ }^{8}$ Jene Mitglieder der DBD, die für Funktionsposten in Frage kamen und von denen bekannt war, daß es in ihren Familien zu gewalttätigen Übergriffen sowjetischer Soldaten gegen Frauen gekommen war, wurden intern oft sorgfältig auf ihre Zuverlässigkeit hin überprüft.

9 Kramer, als Mitarbeiter der DVLF gut informiert, nennt diese Zahlen 1951, ders., Bolschewisierung, S. 88; weitere Zahlen bei Kotow, Agrarverhältnisse, S. 68, Wernet-Tietz, Bauernverband, S. $28 \mathrm{f}$.

10 Statistisches Jahrbuch der DDR 1962, S. $424 \mathrm{f}$, bis 1950 näherte man sich angeblich dem Vorkriegsstand wieder an, blieb aber weiterhin darunter.

11 Merkel, Agrarproduktion, S. 197.

12 Statt vielem: Lehmann, Zwangsarbeiter; Kramer, Bolschewisierung, S. 81-98; Gohl, Deutsche Demokratische Republik, S. 66. 
(seit 1. 3. 1947 ohne Zusatz Vorpommern) und Brandenburg ${ }^{13}$. Bis 1946 hielten sich rund 3,9 Millionen von ihnen auf dem Gebiet der SBZ auf; im Dezember 1947 registrierte man dort rund 4,4 Millionen sogenannte „Umsiedler“, die 24,3 Prozent der Gesamtbevölkerung ausmachten. In allen vier Besatzungszonen und Berlin kletterte ihre Zahl bis 1950 sogar auf 12 Millionen ${ }^{14}$. Für über zwei Millionen Menschen in Mecklenburg standen 1945 nur 247000 voll nutzbare Wohnungen zur Verfügung. Auch in Brandenburg hausten viele in Lehmhöhlen und anderen Behelfsunterkünften ${ }^{15}$. Neben der politischen und sozialstrukturellen ist vor allem die erfahrungsgeschichtliche Bedeutung der Tatsache, daß zwischen 1943 und 1948 fast die Hälfte aller Deutschen zwangsweise unterwegs waren, längst nicht historisch erfaßt ${ }^{16}$.

Die ökonomische und soziale Struktur der landwirtschaftlichen Betriebe auf dem Gebiet der SBZ war bei einem Übergewicht der Gutswirtschaft in Ostelbien insgesamt durchmischt. Während in Sachsen, in der Provinz Sachsen (SachsenAnhalt) und in Thüringen bei teilweise ausgezeichneten Böden bäuerliche Betriebe vorherrschten ${ }^{17}$, war die Gutswirtschaft für Mecklenburg und Brandenburg strukturbestimmend. Die Gutswirtschaft im Norden ist deutlich nach Betriebsgrößen zu unterscheiden: Neben großem Latifundienbesitz mit über 1000 ha Grund und den Gütern des niederen Adels, die einige Hundert ha umfaßten, waren auch staatliche Domänenbauern und ein geringer Anteil an landwirt-

13 In Mecklenburg-Vorpommern stieg die Wohnbevölkerung von 1939 bis 1945 von rd. 1,4 auf 2,1 Mio, das Land war immer noch das am dünnsten besiedelte in der SBZ; Fait, Mecklenburg, in: SBZ-Handbuch, S. 103. In der Provinz (Mark) Brandenburg wurden bis Sommer 1946 zwar 620000 Flüchtlinge und Vertriebene registriert, die Einwohnerzahl von 1939 stieg dadurch aber nur unwesentlich an. Dies., (Mark) Brandenburg, in: SBZ-Handbuch, S. 80. Dennoch gab es Kreise, etwa den Kreis Neubrandenburg, wo 46,2\% der Gesamtbevölkerung auf dem Land lebten und darunter 56,3\% Umsiedler waren, Woderich, Junkerdorf, S. 15.

14 Sch-wartz, Zusammenbruch, S. 43; Steinert, Flucht, S. 557-561. Veraltete, aber nach Anteil der Wohnbevölkerung der Länder ausgewiesene Zahlen bei Kijaschko, Taktik, S. 165, demnach gab es bis 1. 7. 1949 4,3 Mio Umsiedler in der SBZ, die 24,2\% der Gesamtbevölkerung ausmachten; verteilt auf die Länder: Brandenburg 24,8\%, Mecklenburg 43,3\%, Sachsen-Anhalt 24,4\%, Sachsen 17,2\%, Thüringen 24,2\%. Insgesamt stieg die Bevölkerung der SBZ von Jahresende 1939 bis 1946 von 16,7 Mio auf 18,5 und erreichte Ende 1947 mit 19,1 einen nie wieder erreichten Höchststand, Statistisches Bundesamt (Hg.), Sonderreihe, H. 3, Bevölkerungsstatistische Übersichten 1946 bis 1989, S. $24 \mathrm{f}$.

15 Bauerkämper, Bodenreform in der Provinz Mark Brandenburg, S. 266.

16 Zahlen bei ders., Flüchtlinge, S. 286.

17 Die fruchtbarsten Böden lagen in Sachsen-Anhalt, das sowohl einen hohen Stand der Tierzucht als auch Getreideüberschüsse erwirtschaftete. In Sachsen gehörten $193956 \%$ der Betriebe der Größenklasse von 2-20 ha an; es war das führende Land der SBZ in der Viehhaltung, aufgrund der dichten Besiedelung aber kein landwirtschaftliches Überschußgebiet. Am stärksten bäuerlich geprägt war Thüringen, wo $98 \%$ der Betriebe unter 50 ha und insgesamt $84 \%$ der LNF bewirtschafteten, aber auch $20 \%$ der Nutzfläche ausgesprochen arme Böden waren (Thüringer Wald und Rhön). Kramer, Bolschewisierung, S. 82-86; Daten zu Sachsen, Thüringen und Sachsen-Anhalt in den jeweiligen Artikeln in SBZ-Handbuch, S. 127f., 148, 169. Zur Agrarstruktur Sachsens bis 1945: Kluge/Halder, Wirtschaftsordnung, S. 94-100. 
schaftlichem Siedlungsland anzutreffen ${ }^{18}$. In Zahlen bedeutete dies beispielsweise für Mecklenburg folgende agrarische Besitzstruktur: Bis 1945 befanden sich noch $48 \%$ der landwirtschaftlichen Nutzfläche (LNF) und sogar $62 \%$ des gesamten Bodens im Besitz von 2200 bis 2500 Großgrundbesitzern. Der restliche Bodenbesitz verteilte sich 1933 auf 290 staatliche Domänen (116600 ha) und etwa 9500 Großbauern (mit je 20-100 ha); außerdem gab es 193931009 Kleinbauern mit einem Landbesitz unter fünf ha, die insgesamt rund 3,7\% der Nutzfläche bewirtschafteten, und 26680 Mittelbauern (5-20 ha), die auf 18,2\% der LNF arbeiteten ${ }^{19}$. In Thüringen dagegen waren zwei Drittel aller landwirtschaften Klein- und Zwergbetriebe mit weniger als fünf ha Besitz. Nur ein Prozent der landwirtschaftlichen Nutzfläche entfiel auf den Großgrundbesitz ${ }^{20}$. Arbeitete in Mecklenburg noch über die Hälfte der Bevölkerung in der Landwirtschaft - allein die abhängig beschäftigten Landarbeiter mit ihren Familien machten etwa ein Viertel der Gesamtbevölkerung aus -, so betrug dieser Anteil im industrialisierten Sachsen bei Kriegsende nur noch neun Prozent ${ }^{21}$.

Der betriebswirtschaftliche Zustand der bäuerlichen wie der gutswirtschaftlichen Betriebe war im ersten Drittel des 20. Jahrhunderts moderner als er häufig insbesondere zur ideologischen Rechtfertigung der Agrarumwälzung - dargestellt wird ${ }^{22}$. Unübersehbar waren jedoch mit der Gutswirtschaft tiefgreifende soziale und politische Verwerfungen verknüpft. Eine starre Arbeits- und Sozialordnung bescherte großen Teilen der unterbäuerlichen Schichten entweder niedrige Geldlöhne bei gewissen sozialen Sicherungen (System der Deputatlöhne) oder einträglichere Löhne bei höherem sozialen Risiko, in jedem Fall aber meist ein Leben an der Armutsgrenze ${ }^{23}$. Die an Kontrakte gebundenen Landarbeiter waren häufig in die Betriebe integriert, indem sie über eine kleine Wohnung verfügten und ihre Kühe mitgefüttert wurden; im Falle einer Kündigung verloren sie alles. Nach patriarchalischem Muster gewährte Fürsorge bannte in Notlagen häufig die Gefahr, in die Proletarität abzurutschen. Am unteren Ende rangierten die landwirtschaftlichen Saison- und Wanderarbeiter, die zwar höhere Akkordlöhne erhielten, welche jedoch in aller Regel nicht ausreichten, um soziale Risiken abzufedern oder

18 2,7\% aller Betriebe Mecklenburgs hatte eine Größe von über 200 ha (im Deutschen Reich insgesamt 0,5\%), Kramer, Bolschewisierung, S. 83.

19 Fait, Mecklenburg, in: SBZ-Handbuch, S. 104.

20 Die größte Land- und Waldfläche darunter besaß der Herzog von Coburg-Gotha mit rund 17300 ha. Welsh, Thüringen, in: SBZ-Handbuch, S. 169.

21 Fait, Mecklenburg, in: SBZ-Handbuch, S. 104; Welsh, Sachsen, in: SBZ-Handbuch, S. 128.

22 Die Flexibilität der bäuerlichen Betriebe betont Kluge, „Die Bodenreform ist in erster Linie“, S. $104 \mathrm{f}$., den vergleichsweise modernen betriebswirtschaftlichen Zustand der Gutsbetriebe unterstreicht Kuntsche, Entwicklung, dazu auch die Beiträge von Klemm und Achilles in Reif (Hg.), Agrargesellschaft, sowie Heß, Junker, S. 313-316.

23 Zur Differenzierung Flemming, Klasse, S. 393 f.; als Beispiel für einen von vielen Beiträgen Max Webers zum Thema: ders., Entwicklungstendenzen; Wunderlich, Farm Labor, passim; für die Verhältnisse bis zum Beginn des 20. Jahrhunderts die volkskundlichen Beiträge in: Rach/Wessel (Hg.), Bauer und Landarbeiter; zum Konfliktverhalten der Landarbeiterschaft in Pommern bis 1921: Kölling, Familienwirtschaft; für Mecklenburg: Steinmann, Bauer. 
eine Familie zu gründen und zu versorgen ${ }^{24}$. Da ein Teil des Gründungspersonals der DBD dieser sozialen Schicht der ungesicherten Land- und Wanderarbeiter entstammte, sei auf ihre soziale Lage besonders hingewiesen. Bis zum Ersten Weltkrieg trug Auswanderung dazu bei, diesen potentiellen sozialen Sprengstoff zu entschärfen. Von 1871 bis 1914 verlor Mecklenburg ein Siebtel seiner Bevölkerung, ganz überwiegend Landarbeiter, durch Auswanderung ${ }^{25}$.

Die sozialen und kulturellen Dimensionen der Gutswirtschaft bis 1945 sind bislang nicht umfassend ausgeleuchtet ${ }^{26}$. Max Webers Diktum, wonach die „ostelbischen großen Güter [...] keineswegs nur Wirtschaftseinheiten, sondern lokale politische Herrschaftszentren" waren, bleibt nach wie vor gültig ${ }^{27}$. Nach dem Ende des Krieges wurde die politische Mitverantwortung der ostelbischen Gutsherren an der Machtergreifung Hitlers von den kommunistischen Kräften, die nun ihrerseits auf dem Weg zur Macht waren, dazu instrumentalisiert, auf eine völlige ökonomische und politische Liquidierung des Großgrundbesitzes zu drängen. Die existentielle Not auf dem Land ebenso wie die Konsumenteninteressen in den Städten ließen sie hoffen, daß dafür 1945 so günstige Ausgangsbedingungen wie nie zuvor bestünden.

Auf die landwirtschaftliche Lage wirkte die Herrschaftspraxis der sowjetischen Besatzung ein. $\mathrm{Da}$ die Kreiskommandanturen innerhalb ihrer Zuständigkeiten relativ selbständig Befehle erlassen konnten, war eine zentrale Regelung von oben nach unten und eine einheitliche in den verschiedenen Kreisen nicht gewährleistet. Die SMAD und ihre Organisationen in den Ländern und Provinzen erließen unzählige Anweisungen, von denen anfangs viele die Landwirtschaft betrafen ${ }^{28}$. Die Befehle widersprachen sich teilweise, schon der nächste machte oft die vorangegangenen zu Makulatur; bei Nichtbefolgen drohten jedoch harte Strafen. Erste Befehle vom 3. und 22. August 1945 stellten "Sabotageakte" bei der Ernte unter schwerste Strafen ${ }^{29}$. Am 18. August wurde ein Todesurteil gegen einen Parchimer Bauern bekannt gegeben, dem man vorwarf, er habe in betrügerischer Absicht über 30 ha Aussaatfläche verheimlicht, um sich der dafür fälligen Getreideablieferung zu entziehen ${ }^{30}$. Diese dirigistischen Praktiken hoben sich in der Wahrnehmung der Deutschen vom vergleichsweise elastischen System der nationalsozialistischen Ernährungswirtschaft ab; sie stießen auf wenig Gegenliebe, erschwerten die politische Wirksamkeit der Besatzungsherrschaft und schmälerten die Akzep$\operatorname{tanz}$ der protegierten Kommunisten dauerhaft.

${ }^{24}$ Flemming, Fremdheit; Weiland, Schicksal; dies., Lage; dies., Wanderarbeit.

25 Steinmann, Bauer, S. 234; Polzin, Kapp-Putsch, S. 27.

26 Besser erforscht ist das System der Gutsherrschaft bis 1900: Überblick bei Rösener, Bauern, S. 137-156, 161 f.; Heß, Junker; Reif (Hg.), Agrargesellschaft; Kaak, Gutsherrschaft.

27 Weber, Entwicklungstendenzen, S. 471.

28 Quantitativ rangierten sie hinter den Bereichen Gewerbe und Verwaltung. Vgl. die $\mathrm{Zu}$ sammenstellung der offenen, also nicht der "geheimen" und "streng geheimen" Befehle des Obersten Chefs der SMAD von Foitzik; Inventar, hier S. 54 f. der Einleitung.

29 Foitzik, Einleitung, S. 69 f.

30 Laufer, UdSSR, S. $29 \mathrm{f}$. 


\section{Parteigründungen und Blockpolitik}

Mit dem Befehl Nr. 2 vom 10. Juni 1945 gestattete die SMAD in ihrem Besatzungsgebiet die Gründung von „antifaschistischen Parteien“ sowie „freien Gewerkschaften und Organisationen "31. Schon tags darauf wandte sich das ZK der KPD in einem „Manifest" an die Öffentlichkeit, in dem es die politische Wiedergeburt der Partei bekundete und mit einem "Aktionsprogramm“ zur Gründung eines „Blocks der antifaschistischen, demokratischen Parteien“ aufrief ${ }^{32}$. All dies geschah früher als in den Besatzungsgebieten der westlichen Alliierten; ohne jegliche Vorklärung mit ihnen versuchte Stalin, damit seine grundsätzliche Bereitschaft zu einem pluralen politischen Neuanfang im besiegten Deutschland vorzuspiegeln ${ }^{33}$. Daß diese überraschende Aktion als gesamtdeutsche Initiative gemeint war, kann wohl als gesichert gelten ${ }^{34}$. Die USA erkannten einen gesamtdeutschen Schachzug und versuchten ihn offenbar zu unterlaufen ${ }^{35}$.

Die Entwicklung kam auch für die Exil-KPD in Moskau unerwartet. Wilhelm Pieck, der sich zu dieser Zeit noch dort aufhielt, wurde von Georgi Dimitroff dem damaligen Leiter der Abteilung für internationale Information des ZK der KPdSU und einer der Kontaktleute Stalins zu den deutschen Exilanten - erst am 30. Mai über den diesbezüglichen Entschluß des sowjetischen Staatsführers vom 26. Mai informiert ${ }^{36}$. Auch die im Exil in enger Abstimmung mit sowjetischen Genossen laufend überarbeiteten Dokumente über die Vorhaben für Nachkriegsdeutschland, etwa das „Aktionsprogramm des Blocks der kämpferischen Demo-

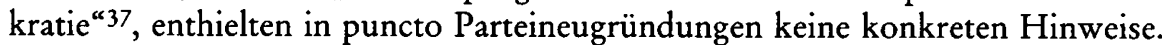
Dies belegt einmal mehr, wie unbedeutend diese Planungen im Zweifelsfall waren, wenn sie mit Stalins kurzfristigen Wünschen kollidierten. Allerdings erwartete auch Pieck um die Jahreswende 1944/45, daß das politische Gesicht eines zukünftigen Deutschland von „antifaschistischen“ Parteien geprägt werde. Die KPDFührung rechnete mit zwei Arbeiterparteien und einer vermutlich katholisch dominierten bürgerlichen Partei. Jenseits der Arbeiterparteien favorisierte sie ein Modell von „Organisationen“, also Verbänden unterhalb der Ebene politischer Parteien, wie es ihr aus der Weimarer Republik vertraut war. Die Parteiführung plante noch im Februar 1945 die Bildung eines „demokratischen Landarbeiter-

31 Befehle des Obersten Chefs der Sowjetischen Militärverwaltung in Deutschland, S. 9 f.

32 Erler u.a. (Hg.), Hitler, S. 120-123, Aufruf der KPD abgedruckt ebd., S. 390-397, Zitate S. 396. Vgl. dazu auch Laschitzka, Demokratie, dort zuweilen veränderte Erstabdrucke einschlägiger Dokumente; die dynamische Komponente des Manifests betont Wettig, Aufschlüsse, S. $158 \mathrm{ff}$., $170 \mathrm{ff}$.

33 Über die Gründung von Parteien war auf keiner Kriegskonferenz der Alliierten gesprochen worden. Erst auf der Konferenz von Potsdam und später im Alliierten Kontrollrat beriet man darüber ausführlich. Die sowjetische Seite verfolgte im Kontrollrat eine Politik, die verbindliche Festlegungen zu Zulassungsmodalitäten oder eine gemeinsame Absprache für Parteineugründungen im jeweiligen Besatzungsgebiet verhindern sollte. Vgl. Koch u. a., Versuch, S. 91-93; Mai, Kontrollrat, S. 128-140; Weber, Geschichte, S. 70 f.

34 Krippendorff, Liberal-Demokratische Partei Deutschlands, S. 22f.; ders., Gründung, S. 290.

35 So Mai, Kontrollrat, S. 128 f.; anders noch Koch u. a., Versuch, S. 91 f.

36 Badstübner/Loth, Wilhelm Pieck-Aufzeichnungen, S. 50; Erler u. a. (Hg.), Hitler, S. 120.

37 Abgedruckt in verschiedenen Fassungen ebd., S. 240-265, 290-304. 
und Bauernbundes“, dessen Gründung die KPD in den Dörfern selbst übernehmen wollte ${ }^{38}$. Nach Stalins Entschluß zu großzügigen Parteigründungen notierte Pieck als dessen Willen am 4. Juni 1945: „Schaffung bes[onderen] Bauernbundes nicht zweckmäßig, sondern innerhalb der Partei einbeziehen "39. Nachweisbare Aktivitäten einzelner Personen in Richtung Gründung einer Bauernpartei, die sich zur Unterstützung an die noch existierenden Landesbauernschaften des nationalsozialistischen Reichsnährstandes wandten, verliefen danach im Sand ${ }^{40}$.

$\mathrm{Daß}$ Stalin zu dieser Zeit keine gesonderte Bauernpartei wünschte, dürfte im Zusammenhang mit den Entwicklungen der Bauernparteien in den stärker agrarisch geprägten ost- und südosteuropäischen Staaten zu sehen sein ${ }^{41}$. Dort verfügten diese Parteien über eine starke politische und kulturelle Verankerung. In Ungarn weigerte sich die „Partei der kleinen Landwirte“, die bei den ersten Wahlen im November 1945 57\% der Stimmen errang, einer umfassenden Kollektivierung zuzustimmen und wurde in der Folge aus der Regierung verdrängt ${ }^{42}$. In Polen verfügten die Bauernparteien, die sich als nationale Untergrundbewegung gegen die deutsche Besatzung profiliert hatten, über eine erhebliche Massenbasis. Im September 1945 hatte sich die wichtigste Partei in "Polskie Stronnictwo Ludowe“ (PSL), eigentlich "polnische Volkspartei“, umbenannt ${ }^{43}$. Ihre Popularität stieg gerade in Konkurrenz zu den um die Kommunisten gruppierten „Lubliner" Parteien (PPR, PPS, SL und SD), insbesondere weil sie den Beitritt zu einem Parteienblock verweigerte, der ihr weniger Mandate versprach, als sie bei Wahlen zu erringen hoffte. Im Vorfeld der - dann völlig manipulierten - Wahlen von 1947 wurden von Geheimpolizei und Miliz 50000-60000 Anhänger der PSL festgenommen ${ }^{44}$. In allen osteuropäischen Volksdemokratien sammelten diese Bauernparteien dank eines hohen Rückhalts in der Bevölkerung Gegner des Kommunismus und stellten gewichtige Konkurrenten um die politische Macht dar. Weder Stalin noch der KPD, die den Ehrgeiz besaß, Arbeiter- und Bauernpartei zugleich zu sein, konnte 1945 an der Gründung einer Bauernpartei gelegen sein.

Unmittelbar nach dem Plazet der SMAD entstanden wenige Tage nach der KPD am 15. Juni wieder eine Sozialdemokratische Partei45 und kurz darauf zwei neue bürgerliche Parteien. Eine überkonfessionelle, christlich bestimmte Union

38 Keiderling (Hg.), „Gruppe Ulbricht“, S. 70-72; KPD-Maßnahmeplan für die Arbeit in besetzten Gebieten, 18. 2. 1945, S. 208-215, hier S. 213, ebd., Übersicht über die Aufgaben in besetzten Gebieten, 18. 2. 1945, S. 216-222, hier S. 218.

39 Keiderling (Hg.), „Gruppe Ulbricht“, S. 468-473; dazu auch Bodensieck, Wilhelm Piecks Moskauer Aufzeichnungen.

40 BA DK-1, 8046, Bl. 45 f., Aufruf zur Gründung einer Deutschen Demokratischen Bauernpartei, von Robert F. Eskan aus Hamburg, undatiert [1945].

41 Für ihre Bedeutung in der Zwischenkriegszeit siehe Gollwitzer ( $\mathrm{Hg}$.), Bauernparteien, S. 4 f., 11-18, und die Beiträge von Leblang und Király in diesem Sammelband.

42 Fejtö, Geschichte, Bd. 1, S. 208 f., 216-220, 222 ff.; Király, Movements, S. 430.

43 Verwirrenderweise hieß diese Partei vorher „SL“, also so wie die später gegnerischen Gruppierungen um das Lubliner Komitee, Diepenthal, Volksdemokratien, S. 91 f.; Leblang, Bauernparteien, S. 312-315.

44 Paczkowski, Polen, S. 413-420, hier 413.

45 Malycha (Hg.), Weg, S. XXVI-XXXI; Müller, Sozialdemokratische Partei Deutschlands, S. 460-466. 
(CDU), deren Gründerkreis um den Weimarer Agrarpolitiker Andreas Hermes sowohl frühere Zentrumspolitiker - so Hermes selbst und Jakob Kaiser - wie auch frühere Vertreter liberaler Parteien - Walther Schreiber und Ernst Lemmer aus der DDP - sammelte, veröffentlichte am 26. Juni einen Gründungsaufruf für Gesamtdeutschland und erhielt am 10. Juli die Lizenz ${ }^{46}$. Zum zweiten formierte sich aus einer Vielzahl von Gründungsinitiativen heraus am 16. Juni eine Partei in der Tradition des liberalen Lagers der Weimarer Parteien DDP und DVP, die Liberaldemokratische Partei (LDP). Sie trat für eine strikte Trennung von Staat und Kirche ein und verstand sich dezidiert als nicht-sozialistische Gründung. Nach inhaltlichen Eingriffen der KPD publizierte sie am 5. Juli einen Aufruf47.

Das „Manifest“ der KPD machte den bürgerlichen Parteien die Mitarbeit am Aufbau zur Pflicht. Gewichtiger war jedoch die Bedingung, mit den anderen in einem inhaltlich noch unbestimmten "Block“ der antifaschistisch-demokratischen Parteien zu arbeiten. Der Block trat nach vorbereitenden Gesprächen am 13./14. Juli 1945 erstmals in Vollbesetzung zusammen ${ }^{48}$. Das Diktum vom „Hineingründen" der Parteien in den Block ist treffend, wobei alle Parteien eine hohe Bereitschaft zur freiwilligen Zusammenarbeit mitbrachten. Diese rührte von der Weimarer Erfahrung eines zersplitterten Parteiensystems und der gemeinsam erlittenen Verfolgung während des nationalsozialistischen Regimes her ${ }^{49}$. Nach der Zustimmung zum „Block“-Prinzip kam die SMAD den Wünschen der CDU entgegen, indem sie die von dieser bevorzugte Bezeichnung „Einheitsfront der antifaschistisch-demokratischen Parteien" gestattete ${ }^{50}$. Wenngleich die zentrale Ebene des Blocks von Beginn an Vorrang hatte, versuchte man das Prinzip auch mit einigem Erfolg - in den Ländern fortzuführen; die Erfassung von Kreisen und Orten blieb hingegen immer unzureichend ${ }^{51}$.

46 Vgl. Baus, CDUD, S. 69-98, hier 93; allg. Suckut, Wandel, S. 117-128; Anna Hermes, Und setztet ihr nicht das Leben ein, S. $199 \mathrm{ff}$.

47 Dazu pflegte Waldemar Koch auch Kontakte zur KPD, SAPMO NY 4036/718, Bl. 1, Koch an Vorstand der KPD, 6. 7. 1945; Gründungsaufruf abgedruckt bei Itzerott, LiberalDemokratische Partei Deutschlands, S. 185 f.; vgl. zur Gründungsphase Krippendorff, Gründung, Papke, Liberal-Demokratische Partei Deutschlands, S. 26-31, und auf Aktenbasis Sommer, Liberal-Demokratische Partei Deutschlands, S. 42-45.

48 Einer vorbereitenden Sitzung am 9.7. 1945 war Hermes ferngeblieben, weil die CDU noch über keine Lizenz verfügte; Suckut, Blockpolitik, S. 55 f., Dok. 5-11. Zur DDR-Lesart siehe Benser, Anfänge, S. 756 ff., 761 f.; Köhler/Wetzig, Wesen, S. 231-242.

49 Das „Hineingründen“ zuerst bei Krippendorff, Gründung, S. 83 f. genannt, so auch Sukkut, Blockpolitik, Einleitung, S. 17 f.; auch die Praxis des Hineinkorrigierens in die "gelenkte“ Gründung der LDPD untermauert diese Sicht: Sommer, Liberal-Demokratische Partei Deutschlands, S. 42, 44; anders argumentiert Reinert, Parteien, S. 50. Zur staatsrechtlichen Absicherung der Blockpolitik 1949, die bis zum Lizenzentzug gehen konnte, Grasemann, Theorie, S. 357-365.

50 Beide Begriffe werden im folgenden synonym verwendet.

51 Als Beispiel für einen Länderblock siehe Edition und Darstellung von Reinert zu Brandenburg: Protokolle des Landesblockausschusses, S. 107. Kreisblöcke entstanden schleppend und mit unklaren Befugnissen. Bis 1947 gab es trotz eines Aufrufs des Provinzialblocks vom November 1945 zur Einrichtung von Ortsblöcken so gut wie keine. Diese Feststellung für Brandenburg läßt sich aus der Aktenkenntnis zu Mecklenburg bzw. den Bezirk Schwerin sowie das Land Sachsen und den Bezirk Dresden bestätigen; siehe auch SAPMO NY 4036/736, Bl. 42 f., Zusammenstellung für Semjonow zur „Nationalen Front 
Die Leitlinien der Blockarbeit, wie sie in einer Geschäftsordnung aus der Feder der SPD von den anderen Vertretern akzeptiert wurden, banden die Mitglieder bekanntlich an das Prinzip der Einstimmigkeit. Dieses konnte Konsens fördern und Dominierung verhindern, ermöglichte aber auch Obstruktion ${ }^{52}$. Die programmatische Arbeit des Blocks blieb unbestimmt. Weder der organisatorische Ablauf noch die Frage des Verhältnisses zu den unteren Organisationsebenen des Blocks war festgelegt worden ${ }^{53}$. Das Machtgefälle verschob sich zuungunsten der bürgerlichen Parteien, die zunehmend in politische Differenzen zur KPD gerieten. $\mathrm{Da}$ die Besatzungsmacht unverhohlen die Kommunisten unterstützte, nutzte vor allem diese die verfahrensmäßigen und inhaltlichen Spielräume.

Das Ausfechten politischer Konflikte und die Bildung von Teil-Koalitionen lagen völlig außerhalb der Verfahrensweise des Blocks ${ }^{54}$. Nie gab es Ansätze, ihn mit gesetzgebender Gewalt oder Kontrollbefugnissen auszustatten. Das lag sowohl im Interesse der KPD als auch der bürgerlichen Parteien, die den Block gerade nicht als Ersatz oder Konkurrenz für ein Parlament sehen wollten. Darauf arbeitete die SED später hin, um den parlamentarischen Einfluß von CDU und LDP zurückzudrängen 55 . Da die maßgeblichen politischen Richtlinien von Beginn an stets außerhalb des Blocks - von sowjetischen Stellen bzw. von diesen kontrolliert in der KPD/SED - festgelegt wurden, verpflichtete er die Parteiführungen häufig zum Konsens wider Willen, aus dem es kein Entrinnen gab.

Keine Partei feilte in Zeiten drückender Not an detailreichen Programmen. Alle Gründungsaufrufe enthielten ein Bekenntnis zum „Antifaschismus“, eine Würdigung des Widerstandes gegen den Nationalsozialismus, und äußerten die Bereitschaft, für Wiedergutmachung einzutreten - letzteres umschrieb einen nicht unerheblichen Kernpunkt im Hinblick auf sowjetische Reparationsforderungen. So war es besonders auffällig, daß die KPD in ihrem Aufruf vom 11. Juni 1945 kein kommunistisches Programm nach dem Zuschnitt bekannter Forderungen aus der Weimarer Zeit präsentierte, vielmehr im „Kampf gegen Hunger, Arbeitslosigkeit und Obdachlosigkeit“ auf die „ungehinderte Entfaltung des freien Handels und der privaten Unternehmerinitiative auf der Grundlage des Privateigentums“ setzte $^{56}$. Unter den wirtschaftspolitischen Forderungskatalogen verzichtete nur die LDP auf Eingriffe in großindustrielle Unternehmen und formulierte Vorbe-

des Demokratischen Deutschland“ - so hieß der Block seit Anfang 1949 - vom 21. 1. 1950: Danach bestanden Ausschüsse der NF erst in ca. 2000 von 11900 Gemeinden; besser schnitten die Kreise ab, Schlußlichter waren Sachsen mit 11 Kreisausschüssen bei 35 Kreisen und Sachsen-Anhalt mit nur 5 Kreisausschüssen.

52 Zur Funktion des Blocks: Koch, Der Demokratische Block, S. 281-292; Suckut, Blockpolitik, Einleitung, S. 24-45.

53 Koch, Blockpolitik, S. 4, 7 f.

54 Auch Reinert, Parteien, S. 23, unterstreicht die Absage an bürgerliche Koalitionspolitik. Insofern erscheint Staritz' Begriffsprägung einer "unkündbaren Koalition“ nicht glücklich gewählt, Staritz, Gründung, S. 99.

55 Eine Ausnahme stellt die mit Druck der SMA herbeigeführte Entscheidung in Brandenburg vom Februar 1947 dar, die Blockvereinbarungen als „Autorität“ für die Parlamentsarbeit einstufte und verbindliche Absprachen für sie vorsah, Suckut, Blockpolitik, S. 30f.; Protokolle des Landesblockausschusses, Sitzung vom 24. 2. 1947, S. 85-88.

56 Aufruf des ZK der KPD vom 11. 6. 1945, Erler u.a. (Hg.), Hitler, S. 390-397, Zitate S. 395. 
halte gegenüber Enteignungen landwirtschaftlicher Betriebe einer „übermäßigen Größenordnung“. CDU und SPD hingegen befürworteten eine Verstaatlichung des Bergbaus, "monopolartiger Schlüsselindustrien“ (CDU) und eine Agrarreform ${ }^{57}$.

Das Instrument der Blockpolitik und die Zusammenarbeit mit vormals verhaßten politischen Gegnern zu akzeptieren, bedurfte in den Reihen der KPD einiger Überredungskunst. Viele Kommunisten glaubten, nach der Niederlage Hitlers und dank sowjetischer Rückendeckung stehe nun die Machtübernahme der KPD bevor. Gegen diese Auffassung, die unter Mitgliedern verbreitet war, welche im Land geblieben waren, setzten die Parteiführung und die SMAD auf die disziplinierende Funktion der aus der Sowjetunion eingeflogenen „Initiativgruppen" 58 . So meldete Fritz Selbmann aus Leipzig im September 1945 zwei "Tendenzen“ im Umgang mit dem Block. Die eine sei ihn aufzulösen, die andere, ihn zu einer festen „Organisation zu entwickeln“. „Beide Tendenzen sind falsch. Neben den Parteien gibt es keine Organisationen und der Block kann kein Exekutivorgan sein. Die einzige Aufgabe des Antifaschistischen Blockes besteht darin: Willensträgerin der antifaschistischen Kräfte unter Führung der KPD zu sein!“ Diesen offenen Machtanspruch der KPD gab er allerdings in einem Rundschreiben an die Ortsgruppen nicht weiter. Er forderte sie auf, den Block auf sein eigentliches Arbeitsgebiet zu beschränken, die Erscheinung, ihn als selbständige Organisation zu behandeln, müsse "sofort liquidiert werden." ${ }^{99}$ In den später installierten Länderund Kreisblöcken war häufig „Sektierertum“ der KPD-Vertreter anzutreffen, das in deren ideologischem Herkommen gründete ${ }^{60}$.

Trotz aller aus der unmittelbaren Not geborenen Gemeinsamkeit der Parteien ist unverkennbar, daß über die Art der politischen Zusammenarbeit, die im Block praktiziert werden sollte, grundlegende Meinungsunterschiede bestanden. Im kommunistischen Verständnis war Blockpolitik ein Instrument, dessen sich kommunistische Parteien bedienten, wenn sie in der Minderheit waren, um über eine "Aktionseinheit" von oben andere Organisationen zu gewinnen und unterzuordnen, und um in einer „Aktionseinheit" von unten auch dort ein Forum zur Verbreitung ihres Gedankengutes zu finden und Druck auf die anderen Parteien auszuüben. Die CDU setzte hingegen auf einvernehmliche Lösungen, in deren Rahmen sie ihre Interessen realisieren wollte ${ }^{61}$. Es liegt auf der Hand, daß diese beiden Pole, insbesondere unter dem Eindruck der ständigen sowjetischen Eingriffe, stark divergierten. Die Block-Vorstellungen zumindest eines Teils der CDU-Gründergruppe trugen stark idealistische und auch unrealistische $\mathrm{Züge}^{62}$.

57 Vgl. die Aufrufe von CDU und LDP, abgedruckt in Weber, Parteiensystem, S. 129-132, 185 f.; Baus, CDUD, S. 83-86.

58 Staritz, Gründung, S. 81-87, 100-103; Keiderling, „Gruppe Ulbricht“; Krüger, Arbeit; Baus, CDUD, S. 57-64.

59 SAPMO DY 30 IV 2/15/115, Auszug aus Sekretariatssitzung [der KPD Sachsen], 8. 8. 1945. SAPMO DY 30 IV 2/15/115, Rundschreiben an alle Ortskomitees, gez. Arbeitsausschuss der antifaschistischen Parteien Leipzig, 19. 9. 1945.

60 Siehe z.B. Reinert, Parteien, S. 46.

61 Richter, Ost-CDU, S. 68-71, vage hingegen Reinert, Parteien, S. 24-28.

62 Vgl. das Beispiel Theodor Steltzer bei Richter, Ost-CDU, S. 69. 


\section{Frübe agrarpolitische Konzeptionen der Parteien und die Einleitung der Bodenreform}

Mit der offiziellen Einleitung der Bodenreform durch die Gesetzgebung der Provinzialverwaltung Sachsens (seit Oktober 1946 Provinz Sachsen-Anhalt, Juli 1947 Land Sachsen-Anhalt) vom 3. September 1945 wurden sämtliche alternativen oder auch nur modifizierenden Überlegungen Makulatur ${ }^{63}$. Bis zum 10. September folgten alle anderen Länder und Provinzen mit einer entsprechenden Bodenreformgesetzgebung. Bei einigen unerheblichen Abweichungen in den Ländern sah diese unabhängig von der Größe des Wirtschaftsbetriebes die entschädigungslose Enteignung von „Kriegsverbrechern“, „Kriegsschuldigen“, „Naziführern“ sowie „führenden Personen des Hitlerstaates" wie Angehörigen der Regierungen und des Reichstages vor. Außerdem sollte der "gesamte feudal-junkerliche Boden und Großgrundbesitz über 100 ha mit allen Bauten, lebendem und totem Inventar und anderem landwirtschaftlichem Vermögen enteignet" werden ${ }^{64}$. Diese wurden pauschal als „Exponenten des Militarismus, radikalen Nationalismus und Nationalsozialismus" stigmatisiert ${ }^{65}$.

Die Kontrolle des Bodenfonds lag in Händen der Bodenreformkommissionen der Länder bzw. Provinzen, deren Kompetenzen sich durchaus unterschieden. So war die mecklenburgische Bodenreformkommission rechtlich autonom konstruiert, wie in Brandenburg war keine Revisionsinstanz vorgesehen ${ }^{66}$. Der spätere Mitbegründer der DBD, Ernst Goldenbaum, war an der Seite des Kommunisten Hans Warnke stellvertretender Vorsitzender der Landesbodenreformkommission in Mecklenburg. Die Verteilung des Landes zielte auf die Schaffung von Kleinparzellen von maximal $10 \mathrm{ha}$ und ging an landlose Landarbeiter und Neusiedler aus den Städten, an landarme Bauern, deren Flächen aufgestockt wurden, und an sogenannte Umsiedler, die man zu Neubauern machte; ein weiterer Teil des Bodenfonds wurde Kommunen, genossenschaftlichen Einrichtungen und staatlichen Gütern zugeschlagen ${ }^{67}$.

Anfängliche Überlegungen, die Besitzungen erwiesener „Antifaschisten“ unter den Großgrundbesitzern oder deren Angehörige, wie diejenigen, die mit den Widerstandsaktivitäten um den 20. Juli 1944 in Verbindung standen, oder sogar hingerichtet worden waren, via Instruktionen an die Provinzial- und Länderverwaltungen gesondert zu behandeln, versandeten noch im September ${ }^{68}$. Ein „antifaschistischer" Konsens mit den Gutsbesitzern wurde von vornherein ausge-

63 Verordnung in: Um ein antifaschistisch demokratisches Deutschland, S. 132-138, folgende Zitate ebd.

64 Unangetastet blieb der Grundbesitz landwirtschaftlicher Genossenschaften, kirchlicher Einrichtungen und staatlicher Güter für Lehr-, Forschungs- und Zuchtzwecke.

65 Bauerkämper, Antifaschismus, S. 627.

66 Kuntsche, Bodenreform, S. 52, 60 f.; Bauerkämper, Bodenreform in der Provinz Mark Brandenburg, S. 284.

67 Siehe Tabelle 4.

68 So noch in einer Pieck-Notiz vom 29. 8. 1945 über ein Gespräch mit Hoernle, Semjonow und Tschujenkow, dem Leiter der Abteilung Land- und Forstwirtschaft der SMAD, in: Badstübner/Loth (Hg.), Wilhelm Pieck-Aufzeichnungen, S. $56 \mathrm{f}$. Dazu Bauerkämper, Antifaschismus, S. 627-631. 
schlossen. Verhaftungen von Gutsbesitzerfamilien, deren Ausweisungen und Deportationen unterstrichen vielmehr, daß diese mit der Bodenreform als „Klasse“ beseitigt werden sollten ${ }^{69}$. KPD und SMAD nutzten die Bodenreform vor allem dazu, ihre Macht auf dem Land dauerhaft zu etablieren ${ }^{70}$. Trotz der sowjetischen Handschrift war die Bodenreform ein spezifisch auf deutsche Agrarverhältnisse zugeschnittener radikaler Eingriff in die ländliche Eigentumsstruktur. Daher trifft der Begriff der „Sowjetisierung“, verstanden als Übertragung von Merkmalen sowjetischer Herrschaft, insbesondere der Herrschaftstechnik, auf sie nicht $\mathrm{zu}^{71}$.

Die schnelle Einleitung der Bodenreform überraschte alle politischen Kräfte in der SBZ. Anläßlich des ersten Besuches der Leiter der "Initiativgruppen“ Ulbricht, Ackermann und Sobottka in Moskau (5. bis 10. Juni 1945) offenbarten sich in der Frage der Enteignung des Großgrundbesitzes und einer Bodenreform taktische Differenzen. Der „Aufruf“ der KPD für den 11. Juni sah eine Enteignung "der großen Güter der Junker, Grafen und Fürsten“ und eine Landübergabe an „die durch den Krieg ruinierten und besitzlos gewordenen“ Bauern vor. Dagegen zielten die Pläne der KPD-Spitze zu diesem Zeitpunkt laut Ackermanns Erinnerungen nicht auf eine sofortige Bodenreform, wie Stalin sie offenbar forderte ${ }^{72}$. Georgi Dimitroff, Mitbegründer der Einheits- und Volksfrontpolitik, plädierte für eine explizite Ausnahmeformulierung für die „Großbauern“, um diese zu beruhigen ${ }^{73}$. Dies deckte sich mit der bündnispolitischen Bedeutung der Bauern, wie sie Edwin Hoernle in seinem „Agrarprogramm des Blocks der Kämpferischen Demokratie“ im Februar 1945 formuliert hatte ${ }^{74}$. Im Unterschied zu den „Bodenspekulanten“ waren die „Großbauern“, wenn sie zu den „Werktätigen“ gehörten, durchaus den „bündnisfähigen“ Landwirten zuzurechnen, mit denen die Kommunisten zusammenarbeiten wollten. Die KPD wäre schlecht beraten gewesen so schien in Hoernles Analyse der deutschen Agrarwirtschaft durch - sich diese ländliche Führungselite zum Gegner zu machen. Mit der Bodenreform verfolgte die KPD eine Bündnispolitik mit der gesamten Bauernschaft: Denn „kaum [...] eine andere Schicht des deutschen Volkes“, einschließlich der „Großbauern“, sei

69 Ebd., S. 629-632.

70 Vgl. im Unterschied dazu die Interpretationen der DDR-Historiographie, die immerhin in den achtziger Jahren von manch unhaltbaren Sichtweisen, etwa einer „revolutionären Erhebung" der Landarbeiter, abrückte und mit aktengestützten Untersuchungen begann (z. B. Schulz, Probleme). Hier ist nicht zu untersuchen, in welchem Ausmaß die Bodenreform einen "Anfangsmythos" der DDR nährte, demzufolge sie vordringlich zur Integration der Umsiedler und zur Ernährungssicherung gedient habe. Ausläufer dieser beschönigenden Sicht sind weiterhin spürbar, etwa bei Kuntsche, Umgestaltung; im Überblick: Kluge, Die ostdeutsche Bodenreform.

71 Ebenso Bauerkämper, Antifaschismus, S. 277; Vgl. Kluge, Wandel, S. 250-258.

72 Laufer, UdSSR, S. 22; Aufruf abgedruckt in Erler u.a. (Hg.), Hitler, S. 390-397, Zitat S. 396. Nach Laufer, UdSSR, S. 23, ist unklar, ob Stalin mit dieser Formulierung auch die Reaktion der Westalliierten testen wollte. Diese sprachen sich daraufhin immerhin nicht gegen eine Bodenreform aus.

73 Zuerst bei Naimark, Russians, S. 143; Laufer, UdSSR, S. 22; siehe Passage im KPD-Aufruf, 11.6. 1945: „Es ist selbstverständlich, daß diese Maßnahmen in keiner Weise den Grundbesitz und die Wirtschaft der Großbauern berühren werden.“, Erler u.a. (Hg.), Hitler, S. 396.

74 Abgedruckt ebd., S. 311-326. 
„von Hitler so betrogen worden, wie der deutsche Bauer“. „Ohne aufzuhören, die Partei der Arbeiterklasse zu sein, muss die KPD auch zur Partei der werktätigen Bauern werden", stand in ersten Lehrmaterialien der KPD 75 .

Inspektionsreisen Ulbrichts und Semjonows im Juni 1945 zeigten, wie illusorisch es war, auf eine spontane revolutionäre Aktion der landarmen Bauern zu hoffen. Daher verlangte Moskau im Juli die Ausarbeitung eines Gesetzentwurfes zur gezielten Einleitung der Bodenreform ${ }^{76}$. Die Auffassungen von revolutionsbereiten Landarbeitern schossen mit der Forderung nach einer sofortigen „Kollektivierung" weit über die Moskauer Konzeption zur Bodenreform hinaus. Zwar formulierte Ulbricht Kernaussagen des Entwurfes, die Partei war jedoch Ende Juni auf die Durchführung einer Bodenreform weder eingeschworen noch vorbereitet ${ }^{77}$. Semjonow gab sich 50 Jahre später in seinen Memoiren als Verfasser einer Direktive aus, die mündlich oder schriftlich von Stalin am Rande der Potsdamer Konferenz angeregt worden sein könnte ${ }^{78}$.

Eine an Stalin adressierte Fassung trägt das Datum 31. Juli 1945, sie wurde aber offenbar nicht umgehend in die sowjetische Hauptstadt weitergeleitet. Inhaltlich hob sie darauf ab, Stalin zu versichern, daß von dem geplanten Vorgehen insgesamt nur wenige (8671) Eigentümer betroffen wären, diese 1,5\% aller Landbesitzer jedoch $46 \%$ des Bodens besäßen ${ }^{79}$. Semjonow zufolge ging die Erhöhung der Enteignungsgrenze von Varianten, die schon bei 40 und 50 ha ansetzten, dann auf 100 ha angehoben wurden, auf Stalin zurück; dieser habe sich bemüht, die Zahl der politischen Gegner in der Bevölkerung klein zu halten. Die Führungsgremien der KPD wurden erst nach Fertigstellung der Direktive über ihren genaueren Inhalt informiert und faßten ab Anfang August dahingehende Beschlüsse. Diese mündeten in Abstimmung mit sowjetischen Kräften am 20. August in eine vom Sekretariat des ZK festgelegte Bodenreformdirektive, die in einer erweiterten Sitzung am 22./23. des Monats als Weisung an die Landes- und Kreisleitungen weitergegeben

75 SAPMO DY 30 IV 2/7/170, Bl. 221-235, „Die Bedeutung der Bauernschaft in Deutschland“, undatiert [1945/46] mit Korrekturzeichen Reutters, Zitate Bl. 230, 232.

76 Lt. Laufer, UdSSR, S. 23, rief Ulbricht Ende Juni 1945 zu eigenmächtigen Enteignungen auf; Semjonow, Stalin, S. $239 \mathrm{f}$.

77 Vgl. dazu den Richtlinienentwurf zu den dringendsten Aufgaben der KPD auf dem Lande von Reutter vom 3. 7. 1945. Er nennt als Aufgaben: 1. die „Vernichtung der faschistischen Widerstandsnester“, 2. die "Gewinnung der Landarbeiter und werktätigen Bauernmassen für den Aufbau des neuen demokratischen Deutschlands“ und 3. eine "Sicherung" der „Volksernährung “ durch die Hilfe der städtischen Bevölkerung; „jeder Versuch, den Bauern oder Landarbeitern die Bildung von Kollektivwirtschaften nach dem Muster der Kolchosen in der Sowjetunion vorzuschreiben, ist entschieden zu bekämpfen“; SAPMO NY 4182/1059, Bl. 1-6, Zitate Bl. 1-4.

78 Dafür liegt bislang kein Aktenbeleg vor; Laufer, UdSSR, S. 25-27; Semjonow, Stalin, S. 235-237.

$79 \mathrm{Zu}$ Unterschieden in den ersten Entwürfen Ulbrichts, der SMAD und Semjonows siehe Laufer, UdSSR, S. 25-27. Semjonows Memoiren zufolge plädierte Ulbricht für eine 50-haGrenze für Enteignungen (S. 237) - dies wich erheblich von der 150-ha-Grenze ab, wie sie in den Moskauer-Planungen 1944 formuliert worden war. Möglicherweise paßte sich Ulbricht der SMAD-Landwirtschaftsabteilung an, deren Entwürfe im Juli 1945 nur Bauern bis 40 ha unangetastet ließen. 
wurde ${ }^{80}$. Nur nachträglich räumten sowjetische Stellen der KPD ein Mitspracherecht ein, indem die Vorstellungen der „Initiativgruppen“ vom Sommer 1945 in die endgültige Formulierung einflossen. Diese hatten die Vorbehalte aufgegriffen, die auf dem Land gegen die ausnahmslose Errichtung von unrentablen Fünf-HektarParzellen herrschten; man regte an, die Bodenqualität zu berücksichtigen und weniger schematisch vorzugehen. Die SMAD war in diesen nachrangigen Punkten flexibel: Sie gestattete, die Größe der künftigen Parzellen von zunächst maximal 5 ha auf 8-10 ha bei schlechten Böden anzuheben ${ }^{81}$. Offenbar mit Rücksicht auf die bürgerlichen Parteien, rückte Stalin von rigiden Abholzungs- und Landgewinnungsplänen $\mathrm{ab}$ und sah eine Zuteilung von Waldflächen vor ${ }^{82}$. Sowjetische Stellen lehnten es strikt ab, mit dem zur Enteignung vorgesehenen Landbesitz großbetrieblich-genossenschaftliche Bewirtschaftungsformen zu errichten, wie sie die KPD zu Weimarer Zeiten gefordert hatte. Diese Vorstellungen flossen in die Nachkriegsplanungen der KPD seit Mitte 1944 ein und waren dort gewiß nicht gegen sowjetischen Willen bis zum 5 . April 1945 niedergelegt worden ${ }^{83}$.

Kaum waren die inhaltlichen Eckpunkte fixiert, versuchten die Sowjets, die vermeintlich bedeutsame Rolle des ZK der KPD bei der Konzeption der Bodenreform hervorzukehren. Sie verpflichteten den Organisationsapparat der KPD darauf, an der Installierung der Landes- bzw. Provinzial-Bodenreformkommissionen mitzuarbeiten ${ }^{84}$. Um etwaige Widerstände im Berliner Einheitsfrontausschuß zu umgehen, wählte die SMAD den Weg über die Länder ${ }^{85}$. Obwohl für den Start zunächst das Agrar- und "Junkerland“ Mecklenburg ins Auge gefaßt worden war, bevorzugte die KPD dann den Vorstoß in der Provinz Sachsen. Die Provinz rangierte hinsichtlich der Dichte des Großgrundbesitzes zwar weit hinter Mecklenburg und Brandenburg, die KPD war dort aber besser politisch verankert. Außerdem konnte sie dort den Gesetzentwurf auf der konstituierenden Sitzung des Blocks, bei der ein SMA-Offizier anwesend war, zur sofortigen Abstim-

80 Laufer, UdSSR, S. 27-30; vgl. Anweisung des Sekretariates des ZK der KPD, 20. 8. 1945, Benser/Krusch (Hg.), Dokumente, hier: Protokolle des Sekretariats des Zentralkomitees der KPD, Bd. 1, S. 71; Bauerkämper, Bodenreform in der Provinz Mark Brandenburg, S. 272.

81 Laufer, UdSSR, S. 28; Anfang August plädierte das Sekretariat des ZK noch für 5-8 ha Zuteilungen, je nach Qualität des Bodens; Bauerkämper, Antifaschismus, S. 626; ders., Bodenreform in der Provinz Mark Brandenburg, S. $278 \mathrm{f}$.

82 Laufer, UdSSR, S. 30, 32. Stalin hatte vorher erwogen, den Bauern eine flächendeckende Brandrodung zu gestatten, was für deutsche Verhältnisse jedoch unangemessen war. Auf sowjetischen Einfluß ging zurück, daß aus der Anweisung des Sekretariates der KPD vom 20. 8. 1945 eine Passage gestrichen wurde, die die CDU ins Lager der potentiellen Gegner der Bodenreform verwiesen hätte.

83 Erler u.a. (Hg.), Hitler, Dok. 22, S. 224, Dok. 31, S. 295 f., Dok. 33, S. 322 f., Dok. 39 : Richtlinien für die Arbeit der deutschen Antifaschisten in dem von der Roten Armee besetzten deutschen Gebiet, 5. 4. 1945, S. 380-386, hier $385 \mathrm{f}$.

84 Bauerkämper, Bodenreform in der Provinz Mark Brandenburg, S. 272, Laufer, UdSSR, S. $29 \mathrm{f}$.; Beschlüsse in Benser/Krusch, Dokumente, hier: Protokolle des Sekretariats des Zentralkomitees der KPD, Bd. 1, S. 71.

85 So zuerst Suckut, Bodenreform, S. 1082f.; vgl. den sofort zustimmenden Beschluß des Blockes in Mecklenburg, 3. 9. 1945, abgedruckt in: Um ein antifaschistisch-demokratisches Deutschland, S. $139 \mathrm{ff}$. 
mung vorlegen ${ }^{86}$. Trotz der Gegenstimme des liberaldemokratischen Präsidenten der Landesverwaltung, Erhard Hübener, wurde ein Gesetz erlassen.

In die maßgeblich sowjetischerseits lancierte Bodenreform sind also ältere Konzeptionen der KPD eingeflossen. Da die Nachkriegsplanung der KPD auch in anderer Hinsicht für die weitere Untersuchung bedeutsam wird, sollen einige Charakteristika hervorgehoben werden. Ackermanns Entwürfe von Ende 1944 enthielten bereits die Strategie, die die KPD bzw. SED in der Durchführung der Bodenreform und in der weiteren rechtlichen Praxis einschlug. So liefen die rechtlichen Regelungen für die konzipierten Neubauernbetriebe auf ein reines Nutzungseigentum hinaus; sie sahen keine freien Verfügungsrechte über Grundstücke und Inventar vor ${ }^{87}$ und formulierten Eingriffsrechte bis in die zweite nachfolgende Generation hinein, „falls die Erwerber ihren staatspolitischen Pflichten als demokratische Bürger zuwiderhandeln“. Maßnahmen gegen "Saboteure“ waren ausdrücklich vorgesehen: „Enteignet wird ferner der Grund- und Bodenbesitz aller Saboteure der Volksernährung, unabhängig von der Größenklasse. "88 Diese Ausführungen enthalten Kernpunkte einer späteren Stalinisierung der KPD/SED, die in der KPD schon verankert waren und nicht erst von außen durch sowjetische Stellen an sie herangetragen wurden ${ }^{89}$. Aus den Nachkriegsplanungen der KPD geht hervor, welch geringen Stellenwert Agrarpolitik und Bauernfragen in der Führungsspitze der Partei bis Ende 1944 einnahmen. Zwar formulierte Edwin Hoernle seit Mitte 1944 Vorlagen; die Parteispitze, etwa Wilhelm Pieck, scheint sich bis Ende 1944 jedoch weder mit der Frage einer Bodenreform noch einer Bündnispolitik mit den Bauern befaßt zu haben ${ }^{90}$. Nach Präzisierungen des Programms in diesen Punkten im Februar 1945 unterstrich der mit Moskau abgesprochene Aufruf der KPD vom 11. Juni 1945 das Bündnis mit den Bauern"1.

Welche Auffassungen vertraten die anderen politischen Gruppierungen zur Bodenreform? In den Sitzungen des Einheitsfrontausschusses und der Länderblöcke stimmte die SPD in der Frage der Bodenreform weitgehend mit der KPD überein ${ }^{92}$. Obwohl die Konflikte im gemeinsamen Ausschuß von KPD und SPD seit

86 Suckut, Konflikt, S. 1082, sieht sich durch Ulbricht, Bauernbefreiung, Bd. 1, S. 50 ff., bestätigt.

87 Diese Beschränkungen wie die späteren zum Verbot von Verkauf, Teilung oder Verpachtung gleichen jenen, die die nationalsozialistische Erbhofgesetzgebung enthalten hatte; Grundmann, Agrarpolitik, S. 154.

$88 \mathrm{Vgl}$. Aktionsprogramm des Blocks der kämpferischen Demokratie, Entwurf Ackermanns Ende 1944, in: Erler u.a. (Hg.), Hitler, S. 290-297, Zitate S. 296. Bauerkämper datiert gegen anderslautende Meinungen das Ende des antifaschistischen Konsenses Ackermanns auf September 1945. Mir scheint, diesen Konsens hat es nie gegeben; Bauerkämper, Antifaschismus, S. 630.

89 So bes. Hurwitz, Stalinisierung, S. $39 \mathrm{ff}$.

90 Vgl. die Dokumente in Erler u.a. (Hg.), Hitler, S. 222-224, Notizen Sepp Schwabs zu einem Vortrag Hoernles; Ende August entstand eine erste Fassung des „Agrarprogramms des Blocks der kämpferischen Demokratie“, abgedruckt in Hoernle, Bündnis, S. 333-345.

91 Hoernles Beitrag „Die Agrarpolitik des Blocks der kämpferischen Demokratie“, Fassung 4. 2. 1945 in: Erler u.a. (Hg.), Hitler, S. 311-326, Ausarbeitung und Endfassung, ebd., S. 387 ff., S. 390-397.

92 Suckut, Konflikt, S. 1083; Wernet-Tietz, Bauernverband, S. 40, Hermes, Christlich-Demokratische Union, S. 31-33. 
Ende August 1945 zunahmen - also ab dem Zeitpunkt, als die KPD ihre bzw. die sowjetische Variante der Bodenreform durchzusetzen versuchte -, schwenkte die SPD am 19. September auf das Prinzip einer am privatbäuerlichen Kleinbesitz ausgerichteten Bodenreform ein ${ }^{93}$. Zeitgenössische Beobachter der CDU konnten schon vorher keine Unterschiede zwischen KPD und SPD in dieser Frage feststellen ${ }^{94}$. Dennoch wich die KPD-Variante in wesentlichen Punkten von den ursprünglichen Vorstellungen der SPD ab; wirkungsmächtig wurden letztere nicht.

Zwar war im SPD-Gründungsaufruf vage von einer „Einziehung“ des Großgrundbesitzes die Rede ${ }^{95}$, doch wie alle Parteien beschäftigte sich die SPD angesichts der akuten Notlage vordringlich mit anderen Dingen als mit programmatischen Texten. Erst im September befaßte sich der Zentralausschuß mit Agrarfragen ${ }^{96}$. Zu diesem Zeitpunkt waren Entscheidungsfindung und Einleitung der Bodenreform längst gelaufen. Ein Fachausschuß wurde parallel zu der am 30 . August im Einheitsfrontausschuß beschlossenen Sonderkommission zur Bodenreform gebildet ${ }^{97}$. Zu den Berührungspunkten mit der KPD gehörte, daß auch die SPD die Wurzeln von Militarismus und Faschismus im Großgrundbesitz erblickte ${ }^{98}$. Bis zum 19. September trat die SPD im gemeinsamen Arbeitsausschuß mit der KPD für eine entschädigungslose Verstaatlichung des Großgrundbesitzes, für die Beibehaltung großer Betriebsstrukturen und eine etwaige genossenschaftliche oder staatliche Bewirtschaftung, aber gegen eine Landübergabe großen Stils in privatbäuerliche Nutzung ein. Zweifellos zielte die SPD damit auf einen höheren Beitrag zur Ernährung, die sie in der Belassung großbetrieblicher Strukturen besser gewährleistet sah.

Insgesamt waren die SPD-Konzeptionen auf ihre angestammte Parteiklientel ausgerichtet. So hatte Gustav Klimpel, Sekretär des SPD-Zentralausschusses für Agrarpolitik, am 16. Juli 1945 in der SPD-Zeitung „Das Volk“ dafür plädiert, ein Siedlungsprogramm mit ernährungspolitischen Zielen zu verknüpfen. Er ging davon aus, daß angesichts einer drohenden Reagrarisierungspolitik und Industriedemontagen der Alliierten die städtische Bevölkerung nur über diesen Weg ihre Ernährung sichern könne99. Die Siedlung richtete sich vorrangig an städtische Arbeiter und Handwerker, die sich als "Schrebergärtner“ und „Kleintierzüchter" versorgen könnten, hauptberuflich aber in ihrem gewerblichen Berufsfeld bleiben, also keineswegs Kleinbauern werden sollten. Für die Masse der Flüchtlinge und

${ }_{93}$ Malycha, Landwirtschaft, S. 38, 41.

94 Hermes, Christlich-Demokratische Union, S. 31-33.

95 Wernet-Tietz, Bauernverband, S. 37; Gründungsaufruf in: Flechtheim (Hg.), Dokumente, Bd. 3, S. $11 \mathrm{ff}$.

96 Ende August/Anfang September bildete die SPD einen entsprechenden Fachausschuß unter der Leitung von Gustav Klimpel, der im wesentlichen die inhaltlichen Punkte des Kieler Parteitages von 1927 aufgriff, vgl. Malycha, Landwirtschaft, S. 39-41.

97 Hermes, Christlich-Demokratische Union, S. 33.

98 Malycha, Landwirtschaft, S. 40. Siehe bes. Rede Grotewohls vom 14. 9. 1945. Vgl. auch Argumentation Heinrich Hoffmanns vor dem Chef der SMA Thüringen, Generalmajor Kolesnitschenko, 24. 7. 1945, in: Malycha (Hg.), Weg, S. 98-101, hier S. 100.

99 Malycha, Landwirtschaft, S. 40 f. 
Vertriebenen sah die SPD keine Lösung durch Siedlungskonzeptionen, wenngleich sie in den „Richtlinien der Sozialdemokratischen Partei zur Bodenreform“ vom 19. September auch für eine "landwirtschaftliche Neusiedlung" eintrat, die Bauernfamilien im Haupterwerb helfen sollte ${ }^{100}$. Die Sozialdemokraten bevorzugten weiterhin die Überführung des enteigneten Besitzes in staatliches Eigentum und wandten sich gegen eine umfassende Privatisierung. Den Enteigneten sollten kleinere Restbetriebe an anderem Ort unentgeltlich belassen werden ${ }^{101}$.

In den Ländern kritisierten SPD-Mitglieder derweil die Art und Weise der Durchführung der Bodenreform. Nur intern gab man zu bedenken, daß ein Eingriff in die gesellschaftliche Struktur von solcher Tragweite einer gesamtdeutschen Rückversicherung in Form eines einvernehmlichen Kontrollratsbeschlusses bedürfe ${ }^{102}$. Die Vorstellungen der SPD unterschieden sich von denjenigen der KPD ganz deutlich in der bündnispolitischen Dimension ${ }^{103}$. Während die KPD in erster Linie eine radikale ökonomische und politische Entmachtung der „Klasse“ der "Junker" betrieb und mit der Schaffung privatbäuerlichen Kleineigentums die dadurch Begünstigten auf Dauer als Bündnispartner gewinnen wollte, knüpfte die SPD zur Lösung der aktuellen Probleme an Weimarer Konzeptionen an. Das bedeutete eine klientelorientierte Politik der Ernährungssicherung in Erwartung gesamtdeutscher Entwicklungen. Es ist sehr wahrscheinlich, daß sich die einfachen KPD-Mitglieder 1945 eher in der auf verstaatlichte und vergenossenschaftlichte Bewirtschaftung ausgerichteten SPD-Politik wiederfanden als in der sowjetisch gesteuerten Variante der Bodenreform, die eine ihnen eher fremd anmutende kleinbäuerliche Eigentumsstruktur vorsah.

Die Liberaldemokraten konnten sich im Juli 1945 offenbar nur schwer dazu durchringen, den Passus „Unterstellungen von Unternehmen“ unter öffentliche Kontrolle in den Gründungsaufruf aufzunehmen. Schon im Nachsatz steht, dies sei nur „gerechtfertigt, wenn die betreffenden Betriebe hierfür geeignet und reif sind und wenn ein überwiegendes Interesse des Gesamtwohls dies gebietet. Dies gilt auch für landwirtschaftliche Betriebe einer übertriebenen Größenordnung. " 104 Während Waldemar Koch für eine privatkapitalistische Landwirtschaft eintrat, war Wilhelm Külz offenbar bereit, gewisse sozialstrukturelle Veränderun-

100 Allerdings erwähnten diesen Aspekt SPD-Vertreter in den Blöcken durchaus, z. B. Curt Böhme auf der Sitzung des Blockausschusses am 6.9. 1945, in: Malycha (Hg.), Weg, S. 113.

101 Malycha, Landwirtschaft, S. 42. Auch die „Richtlinien der SPD für die Durchführung der Bodenreform“, die der Zentralausschuß am 14.11. 1945 beschloß, wiederholten die Ablehnung der Privatisierung, ebd. S. 43.

102 Malycha, Landwirtschaft, S. 44-48; ders. (Hg.), Weg, S. 16-18, Bericht über die Sitzung des Blocks der antifaschistisch-demokratischen Parteien in Usedom, 22. 9. 1945. Allerdings sah man die Möglichkeit, den Eingriff als „revolutionäres Recht“ im nachhinein zu rechtfertigen.

103 In diesem Sinne auch der ideologische Vorwurf der KPD an die SPD, die Bedeutung der Rolle der Bauernschaft immer "unterschätzt" zu haben; SAPMO DY 30 IV $2 / 7 / 170$, Bl. 221-235, „Die Bedeutung der Bauernschaft in Deutschland“, undatiert [1945], Bl. $225 \mathrm{f}$.

104 Text des Gründungsaufrufes vom 5. 7. 1945 nach einer am 3. 8. 1945 veröffentlichten Fassung abgedruckt bei Itzerott, Die Liberal-Demokratische Partei Deutschlands, S. $186 \mathrm{f}$. 
gen mitzutragen ${ }^{105}$. Insgesamt beschäftigte sich die LDP zu dieser Zeit kaum mit bäuerlichen Problemen ${ }^{106}$. LDP wie CDU sprachen sich in den folgenden Monaten gegen eine entschädigungslose Enteignung aus und befürworteten Sonderregelungen für „antifaschistische“ Großgrundbesitzer, womit sie trotz gleichlautender Beschlüsse der Länderblöcke keinen Erfolg hatten ${ }^{107}$. Beide lehnten die überhastete Form der Durchführung ab und plädierten, als die Bodenreform beschlossene Sache war, zumindest für ein Hinauszögern der Aktion.

Für die CDU hatte sich Andreas Hermes in einer programmatischen Rede zur Parteigründungsveranstaltung am 22. Juli als versierter Agrarexperte und Bauernverbandspolitiker dafür ausgesprochen, jenen Großgrundbesitz beizubehalten, der betriebswirtschaftlich gut geführt werde und dessen Besitzer „fortschrittliche" Gesinnung bewiesen ${ }^{108}$. In der CDU war man davon überzeugt, daß der Großgrundbesitz einen maßgeblichen Beitrag zur Ernährung leiste und für Änderungen in dieser Dimension gesamtdeutsche Regelungen nötig seien. In diesem Sinne und angesichts des sowjetischen Drucks im Block appellierte Hermes daher im September 1945 an den Alliierten Kontrollrat; es seien "die erforderlichen Maßnahmen dort zu treffen, wo ein nicht sachlich begründetes Vorgehen die Ernährungsmöglichkeiten für Millionen von Deutschen zu gefährden geeignet ist" ${ }^{\prime 109}$.

Die agrarpolitische Konzeption der CDU hatte eine "gesamtdeutsche Landesplanung" im Blick, die vorrangig eine ernährungspolitische Grundsicherung betrieb, und dafür auf eine Vielfalt an landwirtschaftlichen Betriebsformen setzte. Diese reichten von Stadtrandsiedlungen über genossenschaftliche Siedlungsvarianten, bäuerliche Privatbetriebe bis hin zu Großgrundbesitz. Wo dies ohne Leistungsminderung geschehen könnte, sprach sich auch Hermes für eine umgehende Aufteilung des Großgrundbesitzes aus. Er unterstrich, daß Enteignungen prinzipiell nicht entschädigungslos erfolgen sollten, räumte aber eine gewisse entnazifizierende Stoßrichtung der Beschlagnahmungen ein; allerdings sollte dies nur dort geschehen, wo eine solche Diskreditierung für Einzelpersonen nachgewiesen sei und nicht auf Sippen- oder Standeshaftung hinauslief ${ }^{110}$. Da die darunter erfaßten Einzelpersonen in der Regel erbberechtigte Familienangehörige der nächsten Generation waren, die meist schon aufgrund ihres Alters in geringerem Maße mit dem Nationalsozialismus verstrickt waren, schränkte dies die Reichweite der Enteignung erheblich ein. Auch ein enger Mitarbeiter von Hermes, Friedrich Karl von Zitzewitz-Muttrin, Sproß einer pommerschen Großgrundbesitzerfamilie, ging von der ungebrochenen Fortexistenz der Großgrundbetriebe aus ${ }^{111}$. Er trat

105 Hoffmann, Bodenreform, S. $993 \mathrm{ff}$.

106 So für Brandenburg, wo die bäuerlichen Mitglieder immerhin fast ein Zehntel ausmachten, Reinert, Parteien, S. 44.

107 Eingehender dazu Suckut, Konflikt, S. 1084-1086; Wettig, Konflikt, S. 117.

108 Suckut, Konflikt, S. 1086.

109 Hermes, Christlich-Demokratische Union, S. 42-46, Zitat 42; Fischer, Andreas Hermes, S. 11.

110 Hermes, Christlich-Demokratische Union, S. 43.

111 Zitzewitz-Muttrin arbeitete bis Juli im Berliner Ernährungsamt, dann in der CDU; Wilde, Friedrich Karl von Zitzewitz-Muttrin, S. 29 f., $32 \mathrm{f}$. Wilde geht nicht auf die Be- 
für die Erhaltung der Betriebsstrukturen ein, ließ eine genossenschaftliche Bewirtschaftung jedoch offen ${ }^{112}$.

Beim Thema Bodenreform kam es seit der Blocksitzung vom 30. August 1945, wo LDP und CDU mit der Bodenreformdirektive überrascht wurden, zu massiven Zusammenstößen zwischen der KPD und den Führungen der bürgerlichen Parteien ${ }^{113}$. Am 13. September 1945 gelang es SMAD und KPD schließlich, eine Resolution im Block verabschieden zu lassen, die für die Öffentlichkeit der SBZ keinen Dissens erkennen ließ114. Freilich waren beide Parteiführungen sowjetischerseits mit der Drohung des Lizenzentzuges massiv unter Druck gesetzt worden; die CDU versuchte hinterher umgehend, in einer anderslautenden Resolution, deren Publikation in der SBZ die SMAD jedoch verhinderte, ihre Zustimmung zu relativieren ${ }^{115}$. Nur in Mecklenburg, wo es die LDP noch nicht gab und der CDU-Landesverband von einem vergleichsweise anpassungsbereiten Vorsitzenden, Reinhold Lobedanz, geführt wurde, verabschiedete der Landesblock eine zustimmende Resolution ${ }^{116}$. Die Diskussion in den Einheitsausschüssen der Länder war zunächst verhalten und nicht von sofortiger einhelliger Kritik der bürgerlichen Parteien geprägt ${ }^{117}$. Je mehr die Einsicht in die Praxis der Bodenreform jedoch zunahm, desto stärker schwollen die kritischen Stimmen der bürgerlichen Parteien an. Da die Vertreter der bürgerlichen Parteien weder auf die Entscheidung noch die inhaltliche Fassung einwirken konnten, verlegten sie sich darauf, gegen die Art und Weise der Durchführung zu protestieren ${ }^{118}$.

Der Konflikt um die Bodenreform kulminierte bekanntlich im November 1945. Andreas Hermes weigerte sich für die CDU, einen gemeinsamen Aufruf des Blocks „Helft den Neubauern“ zu unterzeichnen, wenn nicht zugleich eine Stellungnahme „Mißstände bei der Durchführung der Bodenreform“ damit verknüpft würde ${ }^{119}$. So versuchte die CDU-Führung zu unterstreichen, daß sie nicht

deutung einer Landreform in der Konzeption von Zitzewitz-Muttrin ein, obgleich dieser engster agrarpolitischer Mitarbeiter von Hermes in jener Zeit war. In der DDR-Historiographie firmiert Zitzewitz-Muttrin als Beispiel für die Präsenz der "Junker“ in der CDU, Piskol/Nehrig/Trixa, Umwälzung, S. 42.

112 Piskol/Nehrig/Trixa interpretieren dies als „taktische Variante“, ebd.

113 Wernet-Tietz, Bauernverband, S. $40 \mathrm{f}$.

114 Suckut, Blockpolitik, S. 24f., Dok. 30 u. 31, S. 88-90. Die sowjetisch kontrollierten Parteizeitungen druckten seit Mitte Juli (SPD) bzw. Ende August (LDP und CDU) der Bodenreform im Prinzip wohlgesonnene Artikel; Weber, Umgestaltung, S. 2829-2831.

115 Suckut, Blockpolitik, Dok. 32, S. 90; Suckut, Konflikt, S. 1085 f.; Hermes, ChristlichDemokratische Union, S. 31-33.

116 Kuntsche, Bodenreform, S. 56-62; Suckut, Konflikt, S. 1085; ders., Blockpolitik, S. 64; Wernet-Tietz, Bauernverband, S. 40.

117 So für Sachsen Kluge, „Die Bodenreform ist in erster Linie“, S. 107 f., für Thüringen wird die CDU-Haltung zur Bodenreform als „zögerlich“ charakterisiert, Kaiser, Klientelbildung, S. 121.

118 Wille, Verabschiedung, S. 94, 96; Malycha (Hg.), Weg, S. 112-114, Protokoll einer Thüringer Blocksitzung am 6. 9. 1945; für Brandenburg: Reinert, Parteien, S. 58-62.

119 Suckut nimmt insofern eine Neubewertung des Konfliktes vor, als er stärker darauf hinweist, daß die Landesverbände nicht nur massiv gezwungen worden seien, sondern die Politik der Zentrale bisweilen auf die Landesverbände verwirrend und uneindeutig wirken mußte, Suckut, Konflikt, S. 1087-1095. Die ältere Interpretation des Konfliktes bei 
gewillt war, mit dem sowjetischen Alleingang und der Durchführungspraxis der Bodenreform auch ihre systematische Verdrängung aus den Bodenreformkommissionen nachträglich im Block zu billigen. Damit hätte sie die Legitimität der Agrarumwälzung erhöht und wäre dafür noch politisch in die Pflicht genommen worden ${ }^{120}$. Die Bodenreform zählte jedoch zu den unabdingbaren Vorgaben Stalins für die gesellschaftliche Umwälzung in der SBZ. Als Hermes am 14. Dezember Schukow in einem Brief vorschlug, für die Fünf-Hektar-Stellen längere Zwischenwirtschaften einzurichten, was bedeutete, an die ursprünglichen Betriebsstrukturen anzuknüpfen und sie nicht völlig aufzulösen, statuierte dieser an Hermes und Schreiber, den 1. und 2. Vorsitzenden, ein Exempel: Die CDU-Führer wurden abgesetzt ${ }^{121}$.

Zwischen- wie gemeinwirtschaftliche Arbeitsformen unter den Neubauern wurden nun vehement bekämpft ${ }^{122}$. Außerdem hatte die Bodenreform in der geforderten Übertragung auf die westlichen Zonen - der Antrag dazu war einer von insgesamt nur zweien, den die SPD-Vertreter selbständig Anfang 1946 in den Block einbrachten ${ }^{123}$ - auch eine gesamtdeutsche Zielrichtung. Die Auswechslung der CDU-Führung durch die SMAD infolge dieses Konfliktes und der vorher schon erzwungene Rücktritt von Waldemar Koch trugen auch eine deutschlandpolitische Komponente; zumal sich in der CDU abzeichnete, daß die starre Haltung der Führung in dieser Frage in den Landesverbänden und an der Parteibasis nicht immer Unterstützung fand und die Absetzung ohne große Konflikte vonstatten gehen würde ${ }^{124}$.

Die Besatzer verstanden es auch in den folgenden Jahren, die „reformwilligen“ Kräfte beider Parteien auf Kosten von deren demokratischer Legitimität und Eigenständigkeit zu fördern ${ }^{125}$. Mit der Ablösung von Hermes sank der Stellenwert agrarpolitischer Fragen in der Union beträchtlich. Beim Wechsel an die Führungsspitze hatte Kaiser schon im Dezember 1945 angedeutet, daß sich Hermes in dieser Frage gegenüber der SMAD kompromißbereiter hätte zeigen sollen ${ }^{126}$. Seit dem zweiten Berliner Unionstag im September 1947 stand die Agrarpolitik vollends im Schatten von Kaisers Diktum, die CDU müsse ein „Wellenbrecher des

Hermes, Christlich-Demokratische Union, S. 60-73, 86f.; jetzt Baus, CDUD, S. 245252.

120 Ergänzend zur bislang bekannten Protokollvariante der Blocksitzung vom 22. 11. 1945, abgedruckt bei Suckut, Blockpolitik, S. 102-105, siehe auch Piecks Notizen zur Sitzung, SAPMO NY 4036/715, Bl. 19f., Klarschrift der handschriftlichen Notizen zur 8. Blocksitzung am 22. 11. 1945.

121 Wettig, Konflikt, S. 119; Baus, CDUD, S. 237-244; Wilde, SBZ-CDU, S. 236-253.

122 Trotz beschönigender Gesamtinterpretation wichtig: Kuntsche, „Gemeinwirtschaft“.

123 Suckut, Blockpolitik, S. 26, Protokoll der Sitzung vom 10. 1. 1946, S. 107-109, hier 109.

124 So Suckut, Konflikt, S. 1088-1095. Grotewohl ging offenbar schon im November 1945 davon aus, daß Kaiser den Aufruf unterzeichnen würde, SAPMO NY 4090/500, Bl. 46, Niederschrift über die 8. Sitzung am 22. 11. 1945. Loth, Stalins ungeliebtes Kind, S. $55 \mathrm{f}$. $\mathrm{Daß}$ die Blockparteien 1946 tatsächlich zur Stabilisierung der Neubauernwirtschaften beitrugen, bei Ottofülling, Blockpolitik, S. 590.

125 Weber (Hg.), Parteiensystem, S. 37f., S. 45-47; zur CDU Richter, Ost-CDU, S. 43 f., S. $46 \mathrm{ff}$., S. $53 \mathrm{f}$.

126 Dietze, Entscheidungsstrukturen, S. 51. 
orthodoxen Marxismus “ sein. Die Bestrebungen der Agrarpolitiker in der Union, unter der Landbevölkerung ein großes Wählerreservoir für die CDU aufzutun, fanden unter Kaisers Ägide im Vorstand wenig Beachtung127.

\section{Bodenreform und „Bauernpolitik“ der SED}

\section{Wirtschaftliche und sozialstrukturelle Ergebnisse der Bodenreform}

Die Durchsetzung der Bodenreform war ein langwieriger, sich über Jahre hinziehender Prozeß, der hier nicht im einzelnen zu schildern ist ${ }^{128}$. Den SMAD-Befehlen und weiteren Regelungen zufolge lassen sich verschiedene Phasen unterscheiden, die nicht in gleicher Weise für aller Länder gelten dürften. Die Umsetzung begann zügig im Herbst 1945 mit der Aufteilung der ersten Großgüter. Bis Ende Frühjahr 1946 waren diese in allen Ländern weitgehend erfaßt ${ }^{129}$. Teilweise parallel dazu begann dann eine Phase, die unter dem Signum der Entnazifizierung in größerem Maße auch Privatbetriebe unter 100 ha betraf 130 . Die weitere Ausweisung der enteigneten Gutsbesitzer aus den Dörfern ab Mitte 1947, im Gefolge des Befehls Nr. 201, der SMAD-Befehl zur Stabilisierung der Neubauernhöfe im September 1947 und das angekündigte Ende von Überprüfungen der SMAD waren weitere Etappen der Bodenreform ${ }^{131}$. Sie wurde offiziell mit SMAD-Befehl vom 29. April 1948 zum 1. Juli des Jahres für beendet erklärt ${ }^{132}$. Diese Verlautbarung der SMAD steht auch im Kontext mit den seit dem Frühjahr 1948 kursierenden Gerüchten über eine „zweite“ Bodenreform, die in der Sicht der verunsicherten ländlichen Bevölkerung auf eine Kollektivierung hinauslaufen sollte ${ }^{133}$. Die wirtschaftlichen und sozialen Folgen der Bodenreform, sowie die häufig kompensatorischen politischen Einzelmaßnahmen hielten bis in die fünfziger Jahre hinein an.

Die Bodenreform veränderte die agrarwirtschaftliche und gesellschaftliche Verfassung des ländlichen Raumes so nachhaltig wie kein anderer struktureller Eingriff in der Geschichte der SBZ/DDR ${ }^{134}$. Bis Januar 1950 wurden 3,3 Millionen ha

127 Wilde, Friedrich Karl von Zitzewitz-Muttrin, S. 35 f.

128 Zur Orientierung in der neueren Forschung zur Bodenreform: Bauerkämper (Hg.), „Junkerland in Bauernhand“; bislang liegen weder eingehende Regionaluntersuchungen noch eine umfassende Monographie für die SBZ/DDR vor: Siehe aber zu brandenburgischen Kreisen: Spix, Bodenreform in Brandenburg; Nehrig, Uckermärker Bauern.

129 Grundlegend für diese Phase: Stöckigt, Kampf.

130 Für Sachsen Kluge, „Die Bodenreform ist in erster Linie“, S. $115 \mathrm{f}$.

131 Spix, Bodenreform in Brandenburg, S. 4 f.

132 Inventar, S. 154, zur Einordnung des Befehls auch Foitzik, Einleitung, S. 59.

133 So hatte im Frühjahr 1946 eine neue zweite "radikale“ Bodenreform in Sachsen eingesetzt, die die Zahl der enteigneten Betriebe von 1525 auf 2602 erhöhte; Kluge, „Die Bodenreform ist in erster Linie“, S. 115. Bonwetsch u.a. (Hg.), Politik, S. 167f. Im Zuge der 1. Parteikonferenz der SED waren diese Gerüchte erneut virulent, MLHA BPA Schwerin IV/2/1/33, Protokoll Landesvorstandssitzung SED, 6.2. 1949, Bl. 13 ff., hier Bl. 71; Krebs, Weg, S. $75 \mathrm{f}$.

134 Siehe Tabelle 2. 
Land umverteilt. Dabei waren die Agrarregionen der SBZ von der Bodenreform recht unterschiedlich betroffen ${ }^{135}$ : Wurden in den gutsherrschaftlich geprägten Ländern Mecklenburg und Brandenburg über die Hälfte bzw. über $40 \%$ der Nutzfläche berührt, so gelangte in Thüringen nur 15\% der landwirtschaftlichen Nutzfläche in den Bodenfonds ${ }^{136}$. In Sachsen, wo knapp ein Viertel der Nutzfläche erfaßt wurde, veränderte sich im Zuge der Bodenreform die bestehende kleinbis mittelbäuerliche Struktur kaum ${ }^{137}$.

Die Aufteilung des Großgrundbesitzes konnte zwar im Prinzip auf eine vergleichsweise hohe Akzeptanz hoffen, erregte aber bald aufgrund der rigorosen, gewalttätigen und auffallend planlosen, die wirtschaftliche und kulturelle Substanz zerschlagenden Praxis heftigen Widerstand. Da es weder ein geregeltes juristisches Verfahren noch Appellationsinstanzen gab, führten die Landes- bzw. Provinzialbodenkommissionen und die Bodenkommissionen vor Ort in Abstimmung mit den sowjetischen Kommandanturen ein weitgehend unkontrolliertes Dasein ${ }^{138}$. Eine Feinvermessung der betroffenen und vergebenen Bodenflächen unterblieb 1946 bewußt nach dem Motto - Tempo statt Präzision ${ }^{139}$. Um die Unantastbarkeit der Bodenreform trotz offensichtlich fehlender Rechtmäßigkeit und Legalität zu besiegeln, verboten die sowjetischen Behörden die nachträgliche Änderung auch von krassen Fehlentscheidungen kategorisch. Die Begünstigten sollten um ihr neues Gut nicht fürchten müssen, den Enteigneten keine Hoffnung auf Rückgewinn bleiben.

Die Ziele und regional verfolgten Motive, die mit der Durchsetzung der Bodenreform verknüpft waren, auch ihre prozessualen Verschiebungen im Zeitablauf, sind nicht hinreichend untersucht. Was den Großgrundbesitz anbelangt, ist davon auszugehen, daß es nicht nur um die ökonomische und damit - nach marxistischem Verständnis - um die politische Beseitigung der „Klasse der Junker“ ging; mit der Zerstörung der wirtschaftlichen und kulturellen Basis beseitigte man zugleich die Symbole herrschaftlicher Repräsentanz, die die einstige Macht und den potentiellen Anspruch darauf in Erinnerung riefen: die Gutshäuser und die Grundbücher ${ }^{140}$. Deren Existenz hätte als Zeugnis einer langwährenden Besitz-

135 Siehe Tabelle 1. Trotz methodischer Vorbehalte gegenüber bislang verwendeten Statistiken und Zahlenangaben, greift die Untersuchung auf die bekannten Statistiken zurück, zumal auch das Statistische Bundesamt bislang kein Verfahren entwickelt hat, zu gesicherten neueren Daten zu gelangen.

136 Weitere Zahlen zu Mecklenburg bei Kuntsche, Bodenreform, S. $55 \mathrm{ff}$., passim; Bauerkämper, Die Bodenreform in der Provinz Mark Brandenburg, passim; für Thüringen: Kaiser, Klientelbildung, S. 122-125.

137 Kluge, „Die Bodenreform ist in erster Linie“, S. 117, dort Zahlen zur Zusammensetzung der Enteignungen.

${ }^{138}$ Für Thüringen gibt es Indizien, daß Landespräsident Paul anfänglich versuchte, rechtsstaatliche Prinzipien zu beachten, Kaiser, Klientelbildung, S. 122; in Mecklenburg konnte die Landesbodenkommission weitgehend losgelöst von rechtsstaatlichen Maximen mit Unterstützung der SMAD agieren; vgl. Kuntsche, Bodenreform, S. 60 f.; ders., Unterstützung.

139 Kluge, „Die Bodenreform ist in erster Linie“, S. 115.

$140 \mathrm{Als}$ Zeichen einer veränderten politischen Kultur sieht dies Kaiser, Klientelbildung, S. 129-131. 
kontinuität und Tradition für das umlegitimierende Vorgehen der neuen Herrschaft eine Gefährdung bedeutet.

In die Wahrnehmung der bäuerlichen Bevölkerung grub sich besonders jene zweite Phase der Bodenreform ein, die mit der Begründung der Entnazifizierung zahlreiche Privatbetriebe unter 100 ha Nutzfläche erfaßte. Damit traf die Bodenreform einen beträchtlichen Anteil großbäuerlicher Betriebe, deren Inhaber 1945 unter bündnispolitischen Gesichtspunkten nicht attackiert worden waren ${ }^{141}$. Bis 1950 belief sich die Anzahl der enteigneten Privatbetriebe unter 100 ha auf fast ein Drittel aller Betroffenen. Inwiefern damit tatsächlich eine Schicht erfaßt wurde, die sich als dörfliche Elite mit dem nationalsozialistischen Regime eingelassen hatte, ist bislang nicht untersucht. Die durchschnittliche Betriebsgröße dieser Enteignungen lag bei $29 \mathrm{ha}$, und diese großbäuerlichen Enteignungsfälle machten insgesamt nur einen geringen Anteil (4\%) am gesamten Bodenfonds der Bodenreform aus ${ }^{142}$. Dort allerdings, wo die landwirtschaftliche Struktur überwiegend bäuerlich geprägt war, wie in Thüringen, belief sich diese Enteignungsvariante sogar auf über $40 \%$ der beschlagnahmten Betriebe, bei einer durchschnittlichen Größe von nur 18 ha.

Nach der sowjetischen Konzeption von 1945 zielte die Bodenreform darauf ab, durch Umverteilung zu Lasten möglichst weniger Einzelpersonen möglichst viele zu begünstigen. Immerhin profitierten durch Zuteilungen aus dem Bodenreformfonds vordergründig rund 560000 Einzelpersonen mit ihren Familien. Mit der Bodenreform sollten die traditionellen und gegen kommunistische Agitation weitgehend immunen dörflich-ländlichen Milieus aufgebrochen werden. Die von herkömmlichen ländlichen Führungsgruppen dominierten Gebiete sollten für den "demokratischen" Aufbau gewonnen und möglichst für kommunistische Einflüsse geöffnet werden ${ }^{143}$. Die Verschiebungen in der Sozialstruktur und eine neue Art sozialer Auf- und Abstiegsprozesse, etwa das Einsickern der Großbauern in die Lücke, die die Gutsbesitzer hinterließen, sind in der Forschung bereits beschrieben, wenngleich nicht umfassend analysiert worden ${ }^{144}$. Vielerorts wurden die überlieferten Machtverhältnisse trotz der Bodenreform fortgeschrieben, weil die häufig nichts außer einer Urkunde besitzenden Neubauern am unteren Ende der dörflichen Sozialskala rangierten. Insgesamt war die Solidarität unter denjenigen, die sich nun zwar alle „Bauern“ nannten, aber als Gruppe mit gemeinsamen Interessen nicht existierten, äußerst brüchig, sofern überhaupt vorhanden. Zwar

141 Einer Notiz Piecks über eine Besprechung in Karlshorst vom 29. 8. 1945 zufolge wollte man „Ortsbauernführer persönlich nicht berühren - wenn nicht bes. Schweinehund Anders Kreisbauernführer, die aktive Nazis“, Badstübner/Loth (Hg.), Wilhelm PieckAufzeichnungen, S. $56 \mathrm{f}$., Zitat S. 57.

142 Vgl. Tabelle 2.

143 Zur Führungsschicht zählten neben den Gutsherren auch die groß- und altbäuerliche Bevölkerung, eingesessene Handwerksbetriebe, Gastwirte sowie die Pfarrer und Lehrer.

144 Siehe Bauerkämper, Führungsgruppen; ders., Strukturumbruch; ders., Flüchtlinge; vgl. konzeptionelle Überlegungen von Bauerkämper/Danyel/Hübner, Führungsgruppen. Empirisch besser erfaßt sind die sozialen Verhältnisse der neubäuerlichen Bevölkerung: Bauerkämper, Neubauern; ders., Neubauernprogramm; regionale Studien von Spix, Bodenreform in Brandenburg, und Nehrig, Uckermärker Bauern; von der älteren Literatur siehe Kuntsche, „Gemeinwirtschaft“, und Woderich, Zu den Anfängen. 
halfen viele Altbauern den Neuankömmlingen so gut es ging mit ihren Mitteln aus ${ }^{145}$. Gerade im Süden aber etablierte sich eine ausgesprochene „Neidgesellschaft" aufgrund sehr unterschiedlicher Ablieferungssolls ${ }^{146}$. Die Altbauern erwarteten für ihre Hilfe Gegenleistungen in der gewohnten Form - etwa durch Arbeitsleistung der Neubauern auf den altbäuerlichen Höfen -, die sich mit den ideologischen Vorstellungen von KPD und Besatzern aber nicht vertrugen. Wer fremde Arbeitskräfte beschäftigte, geriet ab 1948 schnell in Verdacht, ein „Großbauer" zu sein. Spannungen zwischen den Ländern wurden gefördert, wenn südliche Altbauern erfuhren, wie ihr wertvolles Vieh, das sie in nördliche Neubauerngebiete abgeben mußten, wegen unsachgemäßer Behandlung häufig einging ${ }^{147}$. Gesellschaftliche Konflikte waren in Sachsen oft auf die „fehlgesteuerte Bodenreform" zurückzuführen ${ }^{148}$. Die Bemühungen der SED wurden durch den Umstand enorm beeinträchtigt, daß sie auf dem Land als Vollstreckerin der Kommandowirtschaft der SMAD galt. Denn die Besatzungsmacht berücksichtigte das wirtschaftliche Chaos auf dem Land kaum. Sie befahl ein rigoroses Erfassungsund Ablieferungssystem und führte strenge Kontrollen durch, als habe sie es mit einer völlig intakten Landwirtschaft zu tun ${ }^{149}$.

Inwiefern mit der Begünstigung bestimmter Gruppen bei der Bodenreform eine gezielte Klientelbildung der Kommunisten bezweckt und erreicht worden ist, müßte noch eingehender erforscht werden. Die alteingesessene mittelbäuerliche Schicht gehörte nicht zu den besonders Begünstigten der Bodenreform. Dies belegt der geringe Landanteil, der aus dem Bodenreformfonds an sie ging, wenngleich die Zuteilung von einst herrschaftlichem Wald einen hohen Prestigewert hatte ${ }^{150}$. Hohe Anteile erhielten hingegen die nichtlandwirtschaftlichen Arbeiter und Angestellten (32,7\%), die sogenannten landlosen Bauern, also die kein Land erbenden Bauern-Kinder, und die Landarbeiter (21,2\%). Diese Gruppen zählen eindeutig zu den von der Bodenreform Begünstigten. Abgesehen von den bäuerlichen Familienmitgliedern dürfte mit ihnen zugleich die Klientel von KPD und SPD großzügig bedacht worden sein ${ }^{151}$. Die Begünstigung dieser Gruppen war in den ursprünglichen Konzeptionen von KPD und SPD noch stärker hervorgekehrt worden als in der sowjetischen Endvariante. Offenbar nutzten die KPDMitglieder vor Ort ihren Handlungsspielraum zur Besserstellung der eigenen Klientel. Gestützt wird diese Hypothese auch durch folgende Überlegung: Die Durchschnittszahlen für diese begünstigten Gruppen fallen zunächst schon aufgrund der wirtschaftlichen Struktur der SBZ regional sehr unterschiedlich aus. Die landwirtschaftliche Struktur brachte es mit sich, daß der Anteil begünstigter

145 So etwa in Brandenburg, Bauerkämper, Bodenreform in der Provinz Mark Brandenburg, S. $288 \mathrm{f}$.

146 Kluge, „Die Bodenreform ist in erster Linie“, S. 116.

147 Kuntsche, „Gemeinwirtschaft“, Bd. 2, S. 209-211, $223 \mathrm{f}$.

148 Kluge, „Die Bodenreform ist in erster Linie“, S. 116.

149 Ebd., S. $114 \mathrm{f}$.

150 Siehe Tabelle 4.

151 Kuntsche erwähnt, daß es bislang ungeklärt ist, warum die kleinbäuerliche Gruppe (2-5 ha) im Verlauf der Mecklenburgischen Bodenreform auf 134000 anschwoll; Kuntsche, Bodenreform, S. 55. 
nichtlandwirtschaftlicher Arbeiter und Angestellter in Mecklenburg und Brandenburg gemessen an der Gesamtzusammensetzung der Landempfänger niedriger war als im stärker industrialisierten Süden. Damit war jedoch der Anteil dieser Begünstigtengruppe gerade in den Stammregionen der organisierten Arbeiterbewegung höher als in den nördlichen Landesteilen ${ }^{152}$.

Im Hinblick auf eine Klientelbildung für KPD/SED interessiert vor allem die Gruppe der Neubauern, die auch Flüchtlinge und Vertriebene umfaßte. Insgesamt wurden in der DDR bis zum 1. Januar 1950210276 Neubauernstellen geschaffen ${ }^{153}$, darunter gut 90000 für sogenannte Umsiedler. Entsprechend der Aufteilung des Bodenreformfonds gab es wiederum erhebliche Unterschiede zwischen den Ländern. In Mecklenburg machten die Neubauern fast $90 \%$ der durch die Bodenreform mit Land Bedachten aus, in Thüringen stellten die Neubauern rund ein Fünftel der Begünstigten ${ }^{154}$. In der regionalen Verteilung waren die Zahlen der „Umsiedlerbauern“ entsprechend der Bildung des Bodenreformfonds diversifiziert und einer hohen Fluktuation unterworfen: So gab es in Sachsen 1945 gerade mal 5844 „Umsiedler“, die Land erhalten hatten, in Thüringen schrumpfte ihre Zahl von knapp 15000 Anfang 1946 auf 3341 Ende 1948155; in Mecklenburg vervierfachte sich die Zahl der „Umsiedlerbauern“ von 10328 im Januar 1946 zwar auf knapp 40000 bis Anfang 1950 und umfaßte damit knapp 45\% der Begünstigten; angesichts einer Flüchtlings- und Vertriebenenzahl von rund einer Million Menschen in Mecklenburg blieb der tatsächliche Beitrag der Bodenreform zur "Umsiedler"-Integration jedoch äußerst begrenzt ${ }^{156}$. Dennoch zählten offenbar die Flüchtlinge und Vertriebenen insgesamt, in Relation zu ihrem Anteil an der Gesamtbevölkerung, zu den vergleichsweise begünstigten Gruppen ${ }^{157}$.

Die schwierige wirtschaftliche und soziale Lage der Neubauernschaft ist ein eklatantes Beispiel dafür, wie sehr es der SED mißlang, diese stark umworbene Gruppe wirtschaftlich abzusichern und an sich zu binden. In Mecklenburg mußte für vier Fünftel aller Neubauern erst ein Gehöft errichtet werden, nur jeder zweite Neubauer dort hatte überhaupt einen Wohnraum ${ }^{158}$. Trotzdem unternahm die Besatzungsmacht im Frühjahr 1946 alles, um die "Gemeinwirtschaft" der Neubauern, mit der diese sich behalfen, dabei aber nicht die Gutsbetriebe auflösten, zu beenden ${ }^{159}$. Parteimitgliedschaften in der KPD/SED, auf die sich viele aus vordergründigen Motiven einließen, stießen bald an Grenzen ideologischer Überzeugungen. Für die „Umsiedler“ war die Frage der Anerkennung der Oder-Neiße-

152 Zumal Kluge herausgearbeitet hat, daß sich die klein- bis mittelbäuerliche Agrarstruktur Sachsens nicht verändert hat, er also diese bäuerlichen Betriebe nicht zu den Hauptbegünstigten der Bodenreform zählt; Kluge, „Die Bodenreform ist in erster Linie“, S. 117.

153 Tabelle 4, siehe Summe der landlosen Bauern, Landarbeiter und Umsiedler.

154 Ebd.

155 Meinicke, Bodenreform, S. 138.

156 Vgl. Tabelle 4; Kuntsche, Bodenreform, S. 55; Meinicke, Bodenreform, S. 138, die zweite Spalte der dort abgedruckten Tabelle 3 bezieht sich ganz offenkundig auf Mecklenburg und nicht auf Sachsen.

157 Meinicke, Bodenreform, S. 150; vgl. hingegen Bauerkämper, Integration, S. 200-204.

158 Kuntsche, Bodenreform, S. 65.

159 Ders., „Gemeinwirtschaft“, Bd. 2, S. 203-206, 218 und passim. 
Grenze, die den Verlust der Heimat implizierte, eine solche Barriere ${ }^{160}$. Viele Flüchtlinge und Vertriebene unter den Neubauern und SED-Mitgliedern hofften bis in die fünfziger Jahre auf eine Rückkehr in ihre Heimat. Aufgrund betriebswirtschaftlicher Probleme blieb ihr Elan für den wirtschaftlichen Erfolg häufig begrenzt. Dort, wo sie es trotz aller Widrigkeiten schafften, zählten sie später oft zu den vehementen Kollektivierungsgegnern.

Dennoch war mit der Bodenreform eine nicht zu unterschätzende Integration vor Ort verbunden. Die mit ihrer Umsetzung verknüpfte alltägliche Bekämpfung persönlicher und politischer Gegner schweißte die Ausführenden in den örtlichen Bodenreformkommissionen zusammen. Das Ausufern in Korruption ${ }^{161}$ in der „entbürokratisierten“ 162 Situation im Dorf trug dazu bei. Denn die Mitglieder der Kommissionen waren Mitwisser, Mittäter und Mitbegünstigte zugleich. Auch wenn das weitergesteckte Ziel der Zusammenführung der vielen Enteignungsprofiteure mit den kommunistischen Organisatoren der Enteignung weder umfassend noch dauerhaft gelang, bleibt bei den Bodenreformakteuren in den Dörfern ein Integrationserfolg festzuhalten. Für viele DBD-Aktivisten der Parteigründungszeit und Funktionäre waren die Bodenreformkommissionen eine Art politischer Initiationsort. Daher ist dieser Zusammenhang jenseits idealisierender Manier ${ }^{163}$ besonders hervorzuheben.

\section{Die „Bauernpolitik“ der SED vor dem Scheitern?}

Für die organisatorische und wirtschaftliche Absicherung, vor allem aber für die weitere politische Steuerung der Bodenreform standen der KPD/SED seit 1945 zwei wichtige Apparate zur Verfügung, die Bodenreformkommissionen und die Vereinigung der gegenseitigen Bauernhilfe $(\mathrm{VdgB})$, wie der organisatorische Zusammenschluß der zeitgleich mit dem Beginn der Bodenreform gebildeten örtlichen Bauernkomitees der gegenseitigen Hilfe seit dem Sommer 1946 hieß164. Vor Ort bildeten häufig die gleichen Personen das Rückgrat beider Institutionen, Parteilose und „Bürgerliche“ inbegriffen.

In den Bodenreformkommissionen der Dörfer dominierten in aller Regel kommunistische und sozialdemokratische Parteigänger. Zwar überwogen nach einer Statistik vom April 1946 quantitativ die parteilosen Mitglieder, während die Angehörigen bürgerlicher Parteien insgesamt ein Schattendasein führten. Gegen den Willen der kommunistischen Vertreter, die von sowjetischen Behörden als politisch verläßlichere Kräfte gesehen wurden, kam jedoch kaum eine Entscheidung zustande ${ }^{165}$. Der Handlungsspielraum von Vertretern aus der CDU oder LDP wurde durch bestimmte Verfahrensweisen nahezu ausgeschaltet: So mußten die örtlichen

160 Kaiser, Klientelbildung, S. 127 f.; Kuntsche, Bodenreform, S. 65.

161 Kluge, „Die Bodenreform ist in erster Linie“, S. 118.

162 Mit positiver Konnotation in älterer Untersuchung Kuntsches, „Gemeinwirtschaft“, Bd. 1, S. 32.

163 So Reichelt, Blockflöte, S. 28-31.

$164 \mathrm{Zu}$ Bauernkomitees siehe auch Piecks Notizen über eine Besprechung in Karlhorst, am 29. 8. 1945, Badstübner/Loth (Hg.), Wilhelm Pieck-Aufzeichnungen, S. $56 \mathrm{f}$.

165 Siehe Tabelle 3. 
Anträge auf Bodenzuteilungen ebenso wie die Entscheidungen darüber von den Kreis- und Landes- bzw. Provinzialbodenkommissionen bestätigt werden; die Landesbodenkommissionen wiederum waren über die Innenbehörden der Länderverwaltungen gesteuert, die kommunistischen Einfluß gewährleisteten ${ }^{166}$.

Die VdgB fungierte als Arm der SED zur wirtschaftlichen, politischen und juristischen Absicherung der Bodenreform. Vor allem nachdem die Bodenreformkommissionen bis 1947 häufig aufgelöst worden waren, verstetigten die Ausschüsse der VdgB den kommunistischen Einfluß. Man zielte auf die Festschreibung der Umwälzung und wies nachträgliche Korrekturforderungen von Vertretern aus CDU und LPD zurück. Die im Herbst 1945 gebildeten örtlichen Ausschüsse der gegenseitigen Bauernhilfe waren hauptsächlich damit beschäftigt, den Neubauern erste wirtschaftliche Unterstützung zu geben ${ }^{167}$; schließlich war eine zumindest notdürftige Versorgung Voraussetzung dafür, daß die Neubauern ihre gemeinwirtschaftlichen Praktiken zugunsten einer individuellen Wirtschaftsführung aufgaben, wie es SMAD und KPD Anfang 1946 einforderten ${ }^{168}$. Obgleich in den örtlichen Ausschüssen der gegenseitigen Bauernhilfe auch CDU- und LDPMitglieder vertreten waren, war die VdgB-Politik den offiziellen Verlautbarungen zufolge stets identisch mit den Zielen der KPD/SED, die personelle Führung fest in deren Hand ${ }^{169} .1946$ fiel der VdgB im Rahmen der Vorbereitungen zu den Kommunal- und Landtagswahlen eine besondere Aufgabe zu. Neben den Frauenausschüssen und anderen Massenorganisationen bewarb sie sich mit eigenen Listen bei den Urnengängen. Sie war vielerorts auf dem Land die einzige Massenorganisation, die überhaupt präsent war; daher sollte sie mithelfen, sichere Mehrheiten für die SED in den Gemeindevertretungen und Parlamenten zu beschaffen.

Über die ab 19. Juni 1946 von der SMAD öffentlich angekündigten Gemeindebzw. Kreis- und Landtagswahlen war die KPD-Spitze schon am 23. Januar 1946 andeutungsweise informiert worden ${ }^{170}$. In der Hoffnung, durch Stimmenerfolge in vormaligen Hochburgen der Arbeiterbewegung eine Siegeseuphorie auch in andere Gegenden zu tragen, hatte die SMAD einen sorgfältig abgestimmten Terminplan entwickelt. Nach einem Auftakt mit dem "Volksentscheid über die Enteignung ehemaliger Nazis und Kriegsverbrecher" in Sachsen sollten dort am 1. September die ersten Gemeindewahlen stattfinden; eine Woche später, am 8. September, wählten Thüringen und Sachsen-Anhalt, Mitte September dann die

166 Zur Tätigkeit der Landesverwaltung und organisatorischen Durchführung in Mecklenburg siehe Kuntsche, Unterstützung, S. 147-155; ders., Bodenreform, S. 52, 60 f.; Fait, Mecklenburg, in: SBZ-Handbuch, S. 114f.; Krebs, Weg, S. 103. CDU-Mitglieder waren bis März 1946 nicht in brandenburgischen Bodenkommissionen in den Gemeinden vertreten; in der Provinzialbodenkommission saß zwar von Anfang an Schleusener, der aber erst im November in die CDU eintrat; Reinert, Parteien, S. 80, Anm. 162.

167 Wernet-Tietz, Bauernverband, S. 45 ff.; ders., Rolle; Staritz, Vereinigung der gegenseitigen Bauernhilfe, in: SBZ-Handbuch, S. 761; Piskol/Nehrig/Trixa, Umwälzung, S. 73-76.

168 Kuntsche, „Gemeinwirtschaft“, passim, bes. S. 122-127.

169 Wernet-Tietz, Bauernverband, S. 58 f., 75; freilich konnten ehrgeizige und die Profilierung suchende Köpfe wie der VdgB-Generalsekretär Kurt Vieweg eigene Akzente setzen. Scholz, Bauernopfer, S. 61-82, und passim. 1947 drangen CDU und LDP-Mitglieder gezielt in die VdgB, Kurek, VdgB, S. 96.

170 Badstübner/Loth (Hg.), Wilhelm Pieck-Aufzeichnungen, S. 63. 
am wenigsten industrialisierten Länder Brandenburg und Mecklenburg-Vorpommern; am 20. Oktober folgten sämtliche Kreis- und Landtagswahlen ${ }^{171}$.

SMAD-Chef Sokolowski hob die Wahlen in den Rang eines „Testes“ der nunmehr einjährigen „Demokratisierungspolitik“ der SMAD in Deutschland ${ }^{172}$. Er hielt das Abstimmungsverhalten bestimmter Bevölkerungsgruppen für einen Wahlsieg der SED für entscheidend. Dazu zählte neben den Frauen, die rund $61 \%$ der wahlberechtigten Bevölkerung ausmachten, und den Jungwählern gerade auch die bäuerliche Bevölkerung ${ }^{173}$. Den anfänglichen Sympathiezuwachs für die SED unter den neubäuerlichen Bürgern schätzte er als brüchig und zunehmend gefährdet ein, vor allem weil die CDU die bäuerliche Bevölkerung anhaltend umwarb. Die Deutsche Verwaltung für Land- und Forstwirtschaft (DVLF) hatte ihm genügend Gründe für diese kritische Sicht genannt. Auch sie plädierte für eine positive Stimulierung der bäuerlichen Wähler. Daher drängte sie auf eine rasche Eintragung und damit Absicherung des neu erworbenen Landbesitzes in die Grundbücher, auf großzügige Gewährung von Krediten, Viehankäufe in den westlichen Zonen, eine zügige Neuregelung des noch geltenden NS-Erbhofrechtes, Unterstützungen für die VdgB sowie die Einrichtung einer Beschwerdestelle174. Während die Landwirtschaftsverwaltung damit andeutete, daß das Ansehen der SED unter den sowjetischerseits mitzuverantwortenden Mißständen in der Agrarwirtschaft litt, riß die Kritik Tjulpanows, des Chefs der Verwaltung für Information der SMAD, an der politisch-ideologischen Tätigkeit der SED nicht ab. Die Arbeit mit Frauen, Jugendlichen, Angehörigen der „Intelligenz" und nicht zuletzt den Bauern litt ihm zufolge unter erheblichen Mängeln ${ }^{175}$.

Die Strategie der SMAD für einen Wahlsieg der SED sah vielschichtig aus. Bestand für die Durchsetzungskraft der SED in den Städten ein maßgebliches Kriterium darin, wie sich der innerparteiliche Konflikt zwischen ehemaligen SPD- und KPD-Mitgliedern entwickelte, berührte diese Problematik den Wahlausgang auf dem platten Land weniger, da beide Arbeiterparteien dort kaum verwurzelt waren ${ }^{176}$. Die Taktik für die Landregionen sah daher vor, das Wahlvolk unmittelbar mit Versprechungen für die SED gewogen zu stimmen; Nachteiliges über Lebensmittelrationierungen strich die Informationsverwaltung aus den Redemanuskripten bürgerlicher Parteien ${ }^{177}$. Tatsächlich konnte die SED aufgrund ihrer Dominanz in den Selbstverwaltungsorganen und dank offensichtlicher Bevorzugung durch die Besatzer am ehesten glaubhaft vermitteln, daß nur durch sie umgehend legale Hilfe zu erwarten war. Viele Wähler schätzten deshalb den Einfluß der SED auf Fragen der alltäglichen Versorgung höher ein als den der bürgerlichen Parteien. Zum zweiten hing ein positives Ergebnis für die SED auf dem Land ganz erheblich davon ab, inwiefern es gelang, die Wahlchancen von CDU und LPD

171 Braun, Wahlen, S. 381, 383; Creuzberger, Besatzungsmacht, S. 46, 48f.; zum Volksentscheid eingehender ders., Klassenkampf.

172 Creuzberger, Besatzungsmacht, S. 49.

173 Ebd., S. 49 f.; Braun, Wahlen, S. 387.

174 Creuzberger, Besatzungsmacht, S. 50, Anm. 34.

175 Ebd., S. 56.

176 Braun, Wahlen, S. 387.

177 Creuzberger, Besatzungsmacht, S. 72. 
einzuschränken. Den entscheidenden Hebel dafür bedienten die sowjetischen Kommandanturen vor Ort, indem sie die Registrierung von Ortsgruppen bürgerlicher Parteien verweigern und behindern konnten; die Registrierung aber war laut Paragraph 28 der Wahlordnung bei den Gemeindewahlen Voraussetzung für eine Kandidatur ${ }^{178}$. Die Zulassungskriterien unterlagen der Willkür sowjetischer Offiziere. In den kleinen Orten war es besonders schwierig, die erforderlichen 15-25 Gründungsmitglieder beizubringen, deren organisierte Werbung aber nicht ohne vorherige sowjetische Genehmigung erfolgen durfte. Fadenscheinige Anlässe und Begründungen, Ortsgruppen von CDU und LPD nicht zu genehmigen oder nachträglich wieder aufzulösen, gab es genügend.

Bei den Gemeindewahlen erhielt daher rund die Hälfte der bestehenden Grundeinheiten von CDU und LDP ihre Lizenz nicht rechtzeitig. Die LDP konnte in nur 1600 - meist größeren Orten - gewählt werden, die Union in rund 2100 von insgesamt 11600 Gemeinden der SBZ, obwohl sie über 4050 (CDU) und 3100 (LDP) Grundorganisationen verfügten. Die schlechtesten Chancen hatten beide im Bodenreformland Mecklenburg-Vorpommern, wo die LDP nur in 65, die CDU in rund 230 von insgesamt 2404 Orten gegen die SED antreten durfte ${ }^{179}$. Jakob Kaisers Interventionsversuche bei Tjulpanow und im Einheitsfrontausschuß brachten keine handfesten Ergebnisse, sondern allenfalls vage Versprechungen ${ }^{180}$. Erst die Kreis- und Landtagswahlen eröffneten den bürgerlichen Parteien günstigere Ausgangschancen, weil dafür eine Registrierung der Ortsgruppen nicht nötig war.

Um der CDU thematisch dort Paroli zu bieten, wo sie für sich ein besonderes Einflußmonopol beanspruchte, nämlich unter der christlichen Bevölkerung, drängte die SMAD erfolgreich auf eine Modifizierung der kirchenpolitischen $\mathrm{Li}$ nie der SED, vornehmlich hinsichtlich der evangelischen Kirche. Die SED sollte sich flexibel zeigen und hervorkehren, daß sich die Zugehörigkeit zu einer Religionsgemeinschaft durchaus mit einer SED-Mitgliedschaft vertrage ${ }^{181}$. Hochrangige evangelische Meinungsführer wie den Berliner Bischof Dibelius versuchte man ebenso zu wohlgesonnenen Aussagen zu bewegen wie gezielt auch Pfarrer in ländlichen Regionen ${ }^{182}$. Da die evangelische Kirchenleitung als Ausweg schließlich eine weitgehende parteipolitische Zurückhaltung wählte, also auch auf eine eindeutige Wahlempfehlung zugunsten der CDU verzichtete, erhöhte sie damit die Chancen der SED nicht unerheblich ${ }^{183}$. In der prekären Frage der Anerkennung der Oder-Neiße-Grenze schienen Flüchtlinge und Vertriebene Unterstützung eher durch CDU und LDP zu erwarten, weshalb die Informationsverwal-

178 Siehe ebd., S. 61-65; Braun, Wahlen, S. 384 f. Zum sowjetischen Einfluß auf die Wahlordnung siehe: Bonwetsch u. a. (Hg.), Politik, Dok. Nr. 53, S. 230-232.

179 Creuzberger, Besatzungsmacht, S. 94; Braun, Wahlen, S. 385, mit leicht abweichenden Zahlen für Mecklenburg-Vorpommern.

180 Suckut, Blockpolitik, S. 29, S. 160 f., S. 167-170; Weber, Geschichte, S. 141; Creuzberger, Besatzungsmacht, S. 63 f.; Braun, Wahlen, S. 385; vgl. Falter/Weins, Wahlen, S. 219-222.

181 Creuzberger, Besatzungsmacht, S. 72, 76-84.

182 Ebd., S. 76-84.

183 Ebd., S. 84. 
tung Redemanuskripte von deren Wahlkämpfern auf dieses Thema überprüfte ${ }^{184}$. Offenbar gestand die Informationsverwaltung Grotewohl $\mathrm{zu}$, sich dazu am 13. September im „Neuen Deutschland“ zu äußern, während Tjulpanow in dieser Frage den bürgerlichen Parteien jegliche öffentliche Debatte bei Strafandrohung verbieten wollte ${ }^{185}$.

Die Wahlresultate wiesen die SED als eindeutige Siegerin aus. Bei den Gemeinde- und Kreistagswahlen, wo der Wettbewerb der bürgerlichen Parteien besonders behindert worden war, erreichte die SED mit durchschnittlich 57,2 bzw. $51,1 \%$ die absolute Majorität, bei den Landtagswahlen mit 47,6\% eine deutliche relative Mehrheit ${ }^{186}$. Trotzdem war die SMAD mit dem Wahlergebnis unzufrieden. Nur in drei Länderparlamenten errang die SED die überwiegende Zahl der Sitze, in Brandenburg und Sachsen-Anhalt stellten die bürgerlichen Parteien die Mehrheit im Parlament. Zweifellos erzielte die SED in den ländlichen Gebieten die größten Erfolge; auch dort kam ihr ganz offensichtlich die restriktive Praxis gegenüber den Ortsgruppen der „Bürgerlichen“ zu Hilfe ${ }^{187}$. Allerdings zeigte sich bei den Landtagswahlen, bei denen CDU und LDP über bessere Chancen verfügten, daß die Stimmenanteile der SED in den Stadt- und Landkreisen ausgeglichen waren. Das beste Landtagswahlergebnis errang die SED in MecklenburgVorpommern mit 49,5\%. Die CDU erreichte dort mit 34,1\% ebenfalls ihr bestes landesweites Ergebnis, weil der Konfessionsfaktor des katholischen Teils der Flüchtlinge und Vertriebenen für sie sprach und die LDP dort organisatorisch äuBerst schwach vertreten war und nur auf $12,5 \% \mathrm{kam}$. Immerhin ist das Mecklenburger Wahlergebnis für die SED auf dem Land beachtlich. Es deutet mit großer Wahrscheinlichkeit schon auf einen Sympathiebonus bei den durch die Bodenreform begünstigten Gruppen, etwa den Neubauern, hin ${ }^{188}$. Dagegen hatte Pieck schon im Vorfeld der Wahlen nicht mit den Stimmen der Altbauern gerechnet, die in der SED lediglich als das ausführende Organ der sowjetischen Kommandanten zur Eintreibung der harten Abgabesolls sehen würden ${ }^{189}$. Deutlich zeichnete sich außerdem die Tendenz ab, daß die LDP fast ausschließlich in den Städten reüssierte, die CDU hingegen dort, wo sie antreten konnte, vornehmlich in ländlichen Gebieten ${ }^{190}$. Aus der Sicht der Wähler boten die bürgerlichen Parteien offensichtlich einen politischen Gegenentwurf zur SED. So wäre zumindest zu erklären, warum dort, wo nur eine der beiden Parteien antreten konnte, das gesamte bürgerliche Stimmenpotential sich dann auf die eine Partei konzentrierte und nicht

184 Ebd., S. 72. Die Informationsverwaltung hatte die Wahlprogramme der bürgerlichen Parteien mitbestimmt, siehe Bonwetsch u.a. (Hg.), Politik, Dok. Nr. 53, S. 230-232.

$185 \mathrm{Vgl}$. Creuzberger, Besatzungsmacht, S. $99 \mathrm{f}$.

186 Freilich hatten bei einer insgesamt sehr hohen durchschnittlichen Wahlbeteiligung von je 93\% bei den Kommunal- und Landtagswahlen und 91,6\% bei den Kreistagswahlen fast $10 \%$ ungültige Stimmen abgegeben; Creuzberger, Besatzungsmacht, S. 92, leicht abweichende Zahlen bei Braun, Wahlen, S. 386.

187 Creuzberger, Besatzungsmacht, S. 93; Falter/Weins, Wahlen, S. 227-229.

188 Anders für einen brandenburgischen Kreis: Spix, Bodenreform und Wahlverhalten, S. 89.

189 Reinert, Parteien, S. 111; idealisierend: Ottofülling, Blockpolitik, S. $584 \mathrm{f}$.

190 Braun, Wahlen, S. 386 f., 397. 
für die SED zu Buche schlug ${ }^{191}$. Eine methodisch durchaus problematische Gegenüberstellung der Ergebnisse mit den Resultaten der Reichstagswahlen von 1928 deutet darauf hin, daß die LDP dort stark abschnitt, wo vordem die linksliberale DDP, die rechtsliberale DVP und die Wirtschaftspartei im bürgerlichen Lager vorne gelegen hatten. Die CDU schnitt 1946 besonders dort gut ab, wo einst die DNVP oder regionale agrarische Interessengruppen erfolgreich waren. Hinsichtlich der Konfessionsverteilung, die infolge der Massenwanderungen der Nachkriegszeit in Bewegung geraten war, fällt für die CDU ein eindeutiger statistischer Zusammenhang im katholischen Eichsfeld ins Auge ${ }^{192}$. Obgleich dazu eingehendere Untersuchungen ausstehen, ist die Hypothese erlaubt, daß die sozialmoralischen Milieus der Weimarer Zeit bei den ersten freien Wahlen der Nachkriegszeit noch wirkungsmächtig waren und als wahlentscheidende Faktoren einzuschätzen sind ${ }^{193}$.

$\mathrm{Da}$ die VdgB bei der Gründung der DBD eine erhebliche organisatorische Rolle spielte, ist ihr Part kurz zu charakterisieren, zumal die Wahlzulassung von Massenorganisationen das eigentliche Novum an den Wahlen von 1946 war. Die VdgB sollte in ländlichen Gebieten jenen Wähleranteil binden, der nicht von vornherein für die SED stimmen wollte und auf eine vorgeblich überparteiliche Organisation setzte. Sie ließ sich weiter als Instrument gegen ländliche Bewerber der CDU einsetzen. So wurden CDU-Kandidaten in Mecklenburg-Vorpommern zwar genötigt, auf VdgB-Listen anzutreten, es war aber ungewiß, ob sie ein so errungenes Gemeindemandat in Anspruch nehmen durften, wenn keine Ortsgruppe der Partei bestand ${ }^{194}$. Immerhin erreichte die VdgB bei den Landtagswahlen in Mecklenburg-Vorpommern fast 4\% der Stimmen und vergrößerte die Mehrheit der SED im Parlament ${ }^{195}$. Dennoch war die VdgB nicht immer eine zuverlässige Mehrheitsbeschafferin für die SED in ländlichen Regionen. Wie sowjetische Analysen festhielten, hatte sich die VdgB in Brandenburg gegen die SED profiliert, obgleich sämtliche gewählten Abgeordneten SED-Mitglieder waren und sich im Landtag stets mit der SED zusammentaten ${ }^{196}$. Für einige Kreise Mecklenburg-Vorpommerns, aber auch anderer Länder ist zu beobachten, daß in Gebieten, in denen weder CDU noch LDP zu den Wahlen zugelassen waren, sich deren Stimmenpotential offensichtlich auf die VdgB konzentrierte ${ }^{197}$.

191 Siehe z.B. Abstimmungsergebnisse in Mecklenburg-Vorpommern; die CDU konnte offenbar in den Kreisen Ludwigslust und Hagenow, wo die LDP nur bei den Kreistagswahlen nicht antrat, das jeweilige Stimmenpotential der LDP für sich verbuchen; ebd., S. 402; Creuzberger, Besatzungsmacht, S. 97.

192 Im Kreis Worbis errang das Zentrum bei Reichstagswahlen durchschnittlich 60\%, 1946 erhielt die CDU dort 63\%; Braun, Wahlen, S. 387.

193 Für die SBZ siehe ebd.; vorsichtig Falter/Weins, Wahlen, S. 233; für einen Landkreis Spix, Bodenreform und Wahlverhalten, S. 79, $84 \mathrm{f}$.

194 Creuzberger, Besatzungsmacht, S. 67, und Anm. 135.

195 Braun, Wahlen, S. 397.

196 Creuzberger, Besatzungsmacht, S. 97; auffällig ist, daß ausgerechnet zu Brandenburg bislang keine Kreistagswahlergebnisse publiziert sind; Braun, Wahlen, S. 418; Reinert, Parteien, S. 107; vgl. Spix, Bodenreform und Wahlverhalten, S. 82-89.

197 So etwa bei den Kreistagswahlen in den Kreisen Anklam (28,9\% VdgB), Demmin 
Die sowjetischen Wahlanalysen zur Jahreswende 1946/47 waren eindeutig. Die ungeteilte Zustimmung Sokolowskis fand dabei eine mit schonungsloser Offenheit vorgetragene Einschätzung des thüringischen SMA-Chefs, Generalmajor Kolesnitschenko, vom 27. Dezember 1946. Selbst dort, wo die SED wie in Thüringen als Siegerin aus den Landtagswahlen hervorgegangen sei, hielt Kolesnitschenko den bislang erreichten Stand der "Demokratisierung“ des Landes für nicht gesichert. Der errungene Sieg auf dem Land dürfe nicht über die desolate Ausgangsposition der SED hinwegtäuschen. Angesichts der massiven Unterstützung der Informationsverwaltung und der nicht minder starken Behinderung der bürgerlichen Parteien hatte die SMAD ein wesentlich eindeutigeres Ergebnis für die SED erwartet. Kolesnitschenko rief warnend ins Gedächtnis, daß ein bedeutender Prozentsatz an Wählern die SED nur aufgrund persönlicher Versprechungen gewählt habe, "diese ,Kartoffeldemokratie“ möge uns aber nicht blenden“198. Für die sowjetische Sicht war bezeichnend, daß sie sowohl die verfehlte Arbeit der SED mit den Massen als auch den für sie "reaktionären“ Charakter der bürgerlichen Parteien für wahlentscheidend hielt. Nur ein Faktor floß nicht gebührend in ihre Analyse ein, nämlich die tatsächliche Stimmung der Bevölkerung, die mit den politischen Verhältnissen, wie sie sich seit 1945 immer mehr herauskristallisierten, unzufrieden war ${ }^{199}$. Der Wahlausgang soll jedoch nicht über die wahren Machtverhältnisse hinwegtäuschen, die es erlaubten, sich über Wahlresultate hinwegzusetzen. In den Landesregierungen stellte die SED selbst dort die Mehrheit im Kabinett, wo bürgerliche Fraktionen im Landtag in der Überzahl waren ${ }^{200}$.

Um die bäuerliche Bevölkerung nachhaltig politisch beeinflussen und an die Partei binden zu können, hätte diese Ausgangslage eine kluge „Bauernpolitik“ der SED erfordert. Tatsächlich baute die SED ihr ländliches Ortsgruppennetz bis Mitte 1947 organisatorisch aus ${ }^{201}$. Sowohl in den agrarpolitischen Maßnahmen wie in der ideologischen Position steuerte sie 1947 jedoch zusehends in eine Krise, obwohl Landwirtschaftspolitiker von SED und SMAD seit Ende 1946 aus der völlig unzulänglichen Politik in Bauernfragen kein Hehl machten. So resümierte der Abteilungsleiter Landwirtschaft, Rudolf Reutter, anläßlich einer Zusammenkunft mit SED-Vertretern der VdgB im November 1946, daß die SED weit davon entfernt sei, die Bedeutung der „Agrar- und Bauernpolitik“ für die Partei zu erkennen; selbst im Falle der ihr zugeordneten VdgB würden Vertreter der Partei wie etwa auf Betriebsräteversammlungen in Sachsen geschehen - generell alle Bauern samt VdgB pauschal als "reaktionär" verdammen ${ }^{202}$. Offensive Verbesse-

(34,5\%), Neubrandenburg (31,9\%) und im Heimatkreis von Ernst Goldenbaum, Parchim (30,5\%); Aufstellungen bei Braun, Wahlen, S. 419-421.

198 Zitat bei Creuzberger, Besatzungsmacht, S. 107. Siehe auch Foitzik, Struktur, S. 262 f.

199 So Creuzberger, Besatzungsmacht, S. 95.

200 Ebd., S. 118-124.

201 Brauchbar bei Ottofülling, Blockpolitik, die aktengestützten Zahlen, weniger die einseitige Interpretation, S. 585; vom Vereinigungsparteitag bis September 1947 entstanden ca. 4700 neue SED-Ortsgruppen in den Dörfern, Ende 1947 waren etwa 106308 Bauern Mitglieder der SED (6\% der Mitgliederschaft) sowie 64588 Landarbeiter.

202 SAPMO DY 30 IV 2/7/170, Bl. 7 ff., Tagesordnung und Protokollauszug Besprechung vom 8. 11. 1946, datiert auf 21.11. 1946. 
rungen in der Parteiarbeit, wie Reutter hinsichtlich Schulung und Werbung vorschlug, litten 1947 an Desorganisation und Zersplitterung des SED-Landwirtschaftsapparates ${ }^{203}$. Aus diesem Grund schlug der Leiter der DVLF, Edwin Hoernle, im November 1947 die Einrichtung eines zentralen agrarpolitischen Ausschusses unter Beteiligung aller Parteien, der VdgB und der ländlichen Genossenschaften vor, während das Zentralsekretariat seit Ende Oktober die Einrichtung einer reinen Parteikommission präferierte ${ }^{204}$. Erst im Frühjahr 1948 schuf sich die SED damit eine "autoritative" Stelle, die die bisherigen Akteure, die "Agrar- und Bauernpolitik faktisch auf eigene Faust gemacht “ hätten, ablösen sollte 205 .

Für die Agrarwirtschaft war 1947 ein äußerst schwieriges Jahr. Es begann mit schweren Kaltfrösten und plötzlicher Schneeschmelze, die im Oderbruch, der durch die Kampfhandlungen ohnehin arg in Mitleidenschaft gezogen war, zu einer Überschwemmungskatastrophe führten. Im Frühjahr und Sommer folgte eine Dürreperiode, die der Landwirtschaft große Schäden zufügte und ab Mitte 1947 akute Versorgungsengpässe zur Folge hatte ${ }^{206}$.

Politisch viel brisanter war es jedoch, daß sich die SED seit Jahresmitte 1947 zentral wie in den Ländern und vor Ort immer weniger darum bemühte, die für die Arbeiterklientel ohnehin schwer nachvollziehbare bündnispolitische Konzeption gegenüber den Bauern weiterzuverfolgen. Angeheizt durch die angespannte Versorgungslage, machten sich vor allem in den Grundeinheiten immer mehr "sektiererische ${ }^{\text {“ }}$ Tendenzen gegen die Bauernschaft bemerkbar; so berichtete Tjulpanow nach Moskau: „In der Partei, vor allem in den Grundorganisationen, gibt es wegen der Versorgungsschwierigkeiten eine starke antibäuerliche Stimmung. Besonders stark ist das Unverständnis für die Politik der SMA gegenüber den Bauern. Eine Reihe von Maßnahmen in dieser Richtung (materielle Prämien für die Bauern im Falle von Zusatzlieferungen usw.) werden von [einigen] Parteiorganisationen abgelehnt." 207 Freilich war es eine schwierige Aufgabe für die SED, die Durchführung einer strukturellen Umwälzung, deren Bedingungen letztlich die SMAD bestimmte, voranzutreiben und dafür gerade stehen zu müssen. Bei aller berechtigten Kritik ist daher zu sehen, wie leicht es für die Besatzungsverwaltung war, einerseits der SED den Schwarzen Peter zuzuschieben, sich

203 Ein Produkt war dann die von ihm verfaßte Broschüre, Die Bauernpolitik der SED, von 1947.

204 SAPMO DY 30 IV 2/7/20, Bl. 6, Hoernle, Präsident der DVLF, an ZS der SED, Abt. LW, 5. 11. 1947, Bl. $7 \mathrm{f}$., 9, Entwurf einer Vorlage zur Bildung eines agrarpol. Ausschusses beim ZS, 27. 10. 1947, die 10 Genossen, Lehmann, Merker, Reutter, Scholz, Hoernle, Busse, Rau, Wegener, Jadasch und Vieweg vorsah.

205 So Reutter auf der 1. Sitzung der agrarpol. Kommission, 31.3./1. 4. 1948, SAPMO DY 30 IV 2/7/20, Bl. $29 \mathrm{ff}$., stenografische Niederschrift, hier Bl. $31 \mathrm{f}$.

206 Naimark, Russians, S. 161; Ottofülling, Blockpolitik, S. 592 f.; vgl. Malycha, SED, S. 200204.

207 Tjulpanow an Suslow über die Tagung des PV der SED vom 1.-3.7.1947, am 5. 7. 1947; Bonwetsch u.a. (Hg.), Politik, Dok. Nr. 25, S. 109-115, Zitat S. 114 f.; eckige Klammern von Editoren, runde Klammern im Orginal; vgl. auch ebd., Dok. Nr. 28, S. 126 und Bericht Tjulpanows vom 11. 7. 1947, Badstübner/Loth (Hg.), Wilhelm Pieck-Aufzeichnungen, S. 127-129, bes. 129 . 
andererseits im eigenen (agrar)politischen Vorgehen völlig unflexibel zu zeigen ${ }^{208}$. Letzteres traf besonders auf das unbedingte Festhalten an den Ergebnissen der Bodenreform und in diesem Sinne an der weiter mit rigorosen Mitteln verfolgten „Demokratisierungspolitik“ auf dem Land zu. Im Zuge der Vorbereitungen zum II. Parteitag der SED im September 1947 häuften sich Stimmen, die nachträglich eine Auflösung des Großgrundbesitzes für nicht unbedingt erforderlich hielten und damit implizit einräumten, die Bodenreform habe die Versorgungsengpässe mitverursacht ${ }^{209}$. Solche Einschätzungen waren aus sowjetischer Sicht völlig indiskutabel.

Es ist daher sehr wahrscheinlich, daß die SED auf sowjetische Veranlassung hin im Herbst 1947 alles unternahm, um die strukturelle Umwälzung der Bodenreform juristisch endgültig zu fixieren. Die nach dem Wahlausgang 1946 fest installierten Minister aus bürgerlichen Parteien hatten in dieser heiklen Frage 1947 nochmals einen Dissens um die Bodenreform riskiert; sie hofften, ihren politischen Einfluß in die Waagschale werfen zu können ${ }^{210}$. Die SED sah Ende 1947 die juristische Absicherung der Bodenreform gefährdet. So informierte Merker die SED-Landesvorstände:

„Auf dem Gebiet der Bodenpolitik fehlt in denjenigen Ländern, in denen die Landwirtschaftsminister oder deren Ministerialdirektoren den bürgerlichen Parteien angehören, zur Zeit jede Gewähr für eine Zuendeführung und Sicherung der Bodenreform. Weder die Vermessungen noch die Grundbucheintragungen sind beendet. Viele der alten Grundbücher sind noch nicht vernichtet. Der Übergang der landwirtschaftlichen Nebenbetriebe aus der Bodenreform in den Besitz der $\mathrm{VdgB}$ ist noch nicht geregelt. Der Boden in den Bodenfonds ist noch nicht restlos aufgeteilt. Der Bestand hat sich sogar vergrößert."

Das Zentralsekretariat beschloß daher am 3. November 1947 den Fortbestand bzw. im Falle Sachsens die Wiedereinrichtung der Landesbodenkommissionen ${ }^{211}$. $\mathrm{Da}$ die SED in den Bodenkommissionen über eine sichere Mehrheit verfügte und diese wie vordem der Innenverwaltung nun dem Innenministerium unterstanden, schien eine Fortführung der Bodenreformpolitik im Sinne der SED gewährleistet.

Im Vorfeld der DBD-Gründung sind zwei weitere Momente der SED-„Bauernpolitik“ zu nennen. Zum einen verdichteten sich ab dem Jahreswechsel 1947/

$208 \mathrm{Zu}$ diesem Problem siehe auch Naimark, Russians, S. 162.

209 SAPMO DY 30 IV 2/2022/18, Bl. 32 f., Aktennotiz der HA IV, 6. 8. 1947: „Ablehnung der Bauernpolitik in Bezug auf freien Markt“, „Ablehnung des Prämiensystems für die Bauern“, „Ablehnung der Blockpolitik“, „Die Bodenreform hätte zwar zur Beseitigung der Junker, aber nicht zur Beseitigung der großen Güter führen müssen“.

210 Schon im Frühjahr 1947 war es zu Auseinandersetzungen mit der DVLF gekommen, weil sich die bürgerlichen Landwirtschaftsminister (in Thüringen für die CDU Grosse, in Sachsen für die LDP Uhle) gegen eine Ausdehnung der legislativen Kompetenzen der SED dominierten DVLF im Zusammenhang mit dem Ausbau der zentralen Wirtschaftsplanung gewandt hatten; siehe Piskol/Nehrig/Trixa, Umwälzung, S. $103 \mathrm{f}$.

211 MLHA BPA Schwerin IV/L/2/3/122, Bl. $222 \mathrm{f}$., ZS an alle Landesvorstände der SED betr. Reaktivierung der Landesbodenkommissionen, 28.11. 1947, gez. Paul Merker; SAPMO DY 30 IV 2/2022/18, Bl. 42, Aktennotiz über Besprechung mit dem Genossen Lehmann, 11. 11. 1947, höchstwahrscheinlich von Reutter für Merker; Merker und Lehmanns Vorlage auch in SAPMO NY 4036/685, BI. $48 \mathrm{f}$. 
48 Tendenzen, eine rigorose anti-„großbäuerliche“ Politik zu entfachen. Auf einer Innenministerkonferenz in Sachsen im Oktober 1947 forderte Ulbricht die Kleinbauern auf mitzuhelfen, die Gutsbesitzer endgültig aus den Dörfern zu vertreiben $^{212}$. Diese härtere Gangart, die zusehends in eine aktive Bekämpfung der anfangs umworbenen großbäuerlichen Schicht in den eigenen Reihen, vor allem aber in der CDU und in den Genossenschaften mündete, schritt parallel zum Gründungsprozeß der DBD voran.

Zum anderen hatte es die SED aus sowjetischer Sicht bis Jahresende 1947 nicht verstanden, die bäuerliche Bevölkerung an sich zu binden. Die ihr einst gewogene Schicht landarmer Bauern und Landarbeiter hatte sie zu einer Gruppe ihr feindlich gesonnener Kleinbauern gemacht, die mittel- und großbäuerlichen Kreise wandten sich immer mehr der CDU zu${ }^{213}$. Unübersehbar blieb jedoch ein landwirtschaftliches Desaster, weswegen viele Neubauern ihren Besitz verließen, weil jede Hoffnung auf eine geregelte Bewirtschaftung zerstoben war. Altbauern litten unter dem Ablieferungsdiktat, das sie in ein für ungerecht befundenes Schema von Hektargrößen zwängte, völlig starr und selbst in Not- und Härtefällen unnachgiebig. Gegenüber den öffentlichen Verwaltungen fühlten sich die Altbauern in die Defensive gedrängt ${ }^{214}$. Anfang Januar 1948 zog die SED offenbar Konsequenzen. Am 5. Januar berief sie eine Zusammenkunft ein, zu der alle fünf Abteilungsleiter Landwirtschaft der Landesverbände der SED, die Landesvorsitzenden der VdgB, die Hauptabteilung IV Wirtschaft und die Abteilung IVc Landwirtschaft ihres Zentralsekretariates eingeladen waren ${ }^{215}$. Außerdem intensivierte sie in bis dahin nicht dagewesener Weise ihr Schulungsprogramm zu Agrar- und Bauernfragen $^{216}$. In Moskau schien man jedoch nicht mehr davon überzeugt zu sein, daß die SED den wirtschaftlichen und sozialen Sprengstoff, der auf dem Land herangewachsen war, alleine bewältigen könne, zumal sich der Bauernanteil unter der 1,8 Millionen Mitglieder zählenden Partei Mitte 1947 bei nur 5,8\%, der Landarbeiteranteil bei $3,6 \%$ bewegte 217 .

212 Naimark, Russians, S. 163.

213 So auch ebd., S. 161.

214 Siehe Heinks' kurzen Bericht aus Mecklenburg, SAPMO DY 30 IV 2/7/110, Bl. 1, Hausmitteilung Reutter an Merker und Lehmann, 5. 1. 1948.

215 Ebd.

216 So z. B. in Brandenburg, BLHA Rep. 332, Nr. 13, Protokoll der Landesvorstandssitzung am 23./24. 1. 1948.

217 Müller, Sozialistische Einheitspartei Deutschlands, S. 510. 